\title{
Dangerous Zoning and Stability Assessment of Slopes at Antaibao Open Pit Coal Mine in China
}

\section{Zhigang TAO ( $\nabla$ taozhigang1981@163.com )}

China University of Mining \& Technology (Beijing)

keyuan LIU

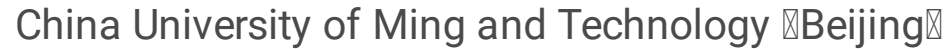

\section{Xiaojie YANG}

China University of Mining and Technology Beijing

Jingtao LI

Geological Survey Center of China Coal Pingshuo Group Go®Ltd囚Pingshuo®China

\section{Peng ZHANG}

College of Civil and Engineering,Qingdao University of Technology ,Qingdao,China

\section{Gengzhao LI}

China University of Ming and Technology Beijing

\section{Research}

Keywords: slope stability, fuzzy mathematics, comprehensive evaluation principle, MSARMA, FLAC3D

Posted Date: December 31st, 2020

DOl: https://doi.org/10.21203/rs.3.rs-135740/v1

License: (c) (i) This work is licensed under a Creative Commons Attribution 4.0 International License.

Read Full License 


\title{
Dangerous Zoning and Stability Assessment of Slopes at
}

\section{Antaibao Open Pit Coal Mine in China}

\author{
TAO Zhigang ${ }^{1,2, *}$,LIU Keyuan ${ }^{1,2}$,YANG Xiaojie ${ }^{1,2}$,LI Jingtao ${ }^{3}$, ZHANG Peng ${ }^{4}$,LI Gengzhao ${ }^{1,2}$ \\ ${ }^{1}$ State Key Laboratory for Geomechanics \& Deep Underground Engineering, China University of Mining \& \\ Technology (Beijing), Beijing 100083, China; 1ky0313@163.com (L.K.); yxjcumt@163.com(Y.X.); \\ 1321220983@qq.com (L.G.) \\ ${ }^{2}$ School of Mechanics \& Civil Engineering, China University of Mining \& Technology (Beijing), Beijing 100083, \\ China; \\ ${ }^{3}$ Geological Survey Center of China Coal Pingshuo Group Go, Ltd, Pingshuo, China, 036000; \\ happyusall@163.com (L.J.) \\ ${ }^{4}$ College of Civil \& Engineering, Qingdao University of Technology, Qingdao, China, 266033; \\ zhangpchn@qut.edu.cn (Z.P.) \\ "Correspondence: taozhigang1981@163.com (T.Z.)
}

\begin{abstract}
With the depletion of shallow coal resources in China, the depths and scales of mining have increased. For several coal mines, the extraction has changed from open-pit to underground. Due to open-pit and underground mining disturbance, landslide disasters frequently occur at high and steep slopes of open-pit mines. The effective identification of danger zone of slope and accurate determination of corresponding stability is important in the field of geotechnical engineering. Herein, Antaibao open-pit coal mine was employed as the research object. Firstly, as per the composition and structural characteristics of on-site slope rock mass, six typical disaster factors were summarized, while the assignment criteria for discrete and continuous variables were divided according to the landslide body characteristics and spatiotemporal distribution. Thereafter, based on the comprehensive evaluation principle of fuzzy mathematics, high and steep side stability in the multi-factor influence regions was comprehensively evaluated, while the spatial division of the unstable region was determined. Finally, the slope potential slip surface in the unstable zone of the western side was utilized as the calculation model object, and sensitivity analysis of the slope impact factor was conducted using the MSARMA method. Therefore, the earthquake as well as drainage rate (groundwater dynamics) were determined as the sensitivity factors. The numerical simulation of FLAC3D finite difference method was performed to analyze the evolution law of displacement field under natural, seepage, and vibrational conditions of the northwest slope.
\end{abstract}

Keywords: slope stability; fuzzy mathematics; comprehensive evaluation principle; MSARMA; FLAC3D

\section{Introduction}

Coal is an important energy resource in the world, there are more and more problems in mining process with the increase of mining depth (Chen et al 2020; Wang et al. 2020a). The Antaibao open-pit Coal mine in Shuozhou, Shanxi has an annual output of 20 million tons of coal, constituting one of the largest open-pit coal mines globally. In the early 1980s, the Antaibao open-pit mine was listed as a Sino-US joint venture project by the Ministry of Coal Industry. Since this venture was agreed upon and initiated, due to the introduction and implementation of international modern enterprise management methods and advanced production technology, this mine has produced stable and high output. The output of single ore has always ranked first in China, contributing highly to the coal production and economic growth of China. Due to the complex engineering geological conditions of Antaibao open pit mine slope, large-scale mining, frequent activities, and multiple construction disturbance factors, as per 
research and analysis of the open-pit engineering geological conditions, the factors that control the stability of the open-pit mine slope include rock body structure characteristics (Hu et al. 2020, wang et al. 2020b), cohesion, internal friction angle (Feng et al. 2020), surface shape, slope height, slope angle, rainfall, presence of groundwater on slopes (Liu et al. 2020), well mining conditions, landslide characteristics of slopes, and seismic intensity. The dangerous slope zoning (Sassa et al.2004;Li et al.2005; Cascini 2008;Cui et al.2009; Jaiswal et al.2011;Whittall et al.2017;Muceku and Jaupaj 2018; Saleem et al.2020;Tang et al.2020) and scientific evaluation of the stability of the mining slope are affected by multiple factors (Byea and Bellb 2001; Pantelidis 2009; Qi et al.2016; Siddique et al.2017; Sarkar et al.2018; Zhu et al. 2020), and has proven to be a prerequisite to ensure the safe and normal operation of the mines. Through the MSARMA (MODIFIED SARMA) method, several factors that already had a high effect on the slope stability and improved stability analysis could be excluded (Yao 2001; Yao et al.2002; He et al.2004), such as slope drainage rate, bulk density of the slope soil, bottom sliding surface cB, $\varphi \mathrm{B}$ value, side sliding surface cs, $\varphi s$ value, and seismic coefficient kc, etc.

Numerous studies have performed related research on the slope stability and have achieved significant results. Fellenius (1957) proposed a Swedish section method that can consider both cohesion and friction, while Sun (1957) suggested a control method of rock mass structure. In 1970, the theory of limit equilibrium and elastoplastic mechanics began to be applied in practice, and a large set of academic viewpoints and methods of engineering geomechanics were formed (Zhang et al. 1981) Since 1980, numerical simulation has been increasingly applied in slope stability analysis and has led to shift from qualitative research to quantitative research on slope deformation and failure mechanism. Sun (2008) used ABAQUS software to analyze the stability of soil slopes. Ma (2008) employed finite difference program software FLAC to simulate and analyze the slope stability. Meng (2008) utilized the SLOPE/W module and fuzzy evaluation in GEO-slope software to analyze and study the stability of rock slopes. Chen (2018) proposed a slope stability analysis method based on the Coupled Eulerian-Lagrangian (CEL) numerical strategy with an energy based criterion. Ersoz (2018) used slope stability probability classification method to evaluate 20 road cuts located in North West Black Sea region of Turkey. Kundu (2018) utilized limit equilibrium method and finite element method under static conditions to analyze the slope stability. Liu (2020) suggested a 2D and 3D slope stability FELEM using elastic finite element stress fields, this method can be applied to solve various slope problems.

At present, the research on stability analysis of open-pit mine slopes is relatively saturated after years of development; however, certain shortcomings still exist. For instance, the stability of open-pit mine slopes is affected by various factors such as excavation, loading, rainfall seepage, and blast load. Through the current analysis methods, mostly one or several of these factors have been separately analyzed. The coupling and analysis of multiple influencing factors have been challenging steps in the stability analysis of open-pit mine slopes. Herein, the fuzzy comprehensive evaluation method was utilized for the fuzzy boundary based on membership. The fuzzy comprehensive evaluation method is based on fuzzy set descriptions, hierarchy of the evaluation object, as well as the evaluation criteria and the ambiguity of the influencing factors. It is also possible to combine qualitative and quantitative factors to expand the range of information and improve the accuracy of risk zoning and evaluation (Tan et al.2011; Wan et al. 2015; Zhang et al. 2015; Zhang et al. 2015; Wu et al. 2017; Du et al.2019). 
The novelty in the current work lies in the fact that the fuzzy comprehensive evaluation method and MSARMA slope stability analysis method were combined to achieve the stability analysis of the complex slope that is affected by multiple factors. The as-proposed analysis method can not only segregate the most dangerous areas, but also screen out several disaster factors that can have a greater impact on the slope based on the site conditions. The focus of the analysis is to understand the effect of these disaster factors on slope stability.

\section{Geological conditions analysis of Antaibao open-pit coal mine}

Antaibao open-pit coal mine is situated at the low mountains and hills of Shuo platform within the Loess Plateau. The terrain is high in the north and low in the south. The altitude is between $1232 \mathrm{~m}$ and $1490 \mathrm{~m}$. The mining area is surrounded by mountains on three sides, forming a small basin (Fig. 1). A multi-stage platform is set at the middle of the slope with the width of each stage being $25-40 \mathrm{~m}$. The single-stage slope is between $20^{\circ}-25^{\circ}$ (Fig. 2).

\subsection{Lithological Characteristics}

According to the drilling results obtained from the study area, in combination with the engineering geological surveys, the rock groups in the area are primarily sandstone, siltstone, and clay rock. The upper part of the mining area is composed of Quaternary sediments and weathered layers, while the lower part is a geological slope with a composite structure comprising of bedrock.

Quaternary sediments are mainly composed of loess-like silt, silty clay, sandstone, mudstone, argillaceous sandstone and coal rock. The silt soil has uniform soil quality, low dry strength, low toughness, and fragile by hand.

The bedrock is mainly composed of sandstone and mudstone. Sandstone joints and fissures are well developed, and nearly vertical joints and fissures can be seen locally. The water absorption reaction is strong, and the part has been weathered into soil, which can be crushed by hand.

The mining area was located on the northwest wing of the Erpu anticline and the anticline strike was $\mathrm{N} 50^{\circ} \mathrm{E}$. The bedding in this area is mainly anti-slope bedding, with oblique cross-slope joints, strike $\mathrm{N} 8^{\circ} \mathrm{W}$, incline $\mathrm{SW}$, and dip of about $15^{\circ}$. This area is dominated by the compressive stress field in the SE-NW direction, while the inclination of the reverse fault is relatively slow at $15^{\circ}-30^{\circ}$ in general.

\subsection{Environmental characteristics}

Meteorological characteristics: The mining area is located at a semi-arid continental climate area of temperate latitude with slight rainfall. The average annual temperature is 5.5 to $6.8^{\circ} \mathrm{C}$, while the annual temperature range is $-32.4^{\circ} \mathrm{C}$ to $37.9^{\circ} \mathrm{C}$. The annual rainfall is 345.3 to $682.2 \mathrm{~mm}$, and the annual average is 428.2 (1934 to 2003 at Shuoxian Weather Station) $449 \mathrm{~mm}$ (1973 to 2005 at Jingping Weather Station), the highest is $757.4 \mathrm{~mm}$, and the lowest is $195.6 \mathrm{~mm}$. The rainfall mainly occurs from July to September and the maximum rainfall intensity can reach up to $87 \mathrm{~mm} /$ day and $478 \mathrm{~mm} /$ month.

According to the aquifer medium and hydrodynamic characteristics, groundwater could be divided mainly into three types: loose surface soil pore water, fissure water among rock layers, limestone karst fissure water.

\subsection{Earthquake magnitude}

Pingshuo Coalfield is located on the northeastern edge of the Ordos Plate, and its surrounding history is an earthquake-prone belt. According to the statistical data on the distribution of 
earthquakes in this area, the $322 \mathrm{~km}^{2}$ area of Pingshuo Coalfield is divided into four earthquake zones. The MHPA (Magnitude Peak Horizontal Acceleration) values of the above four earthquake zones are shown in the table.

\subsection{Factors influencing slope stability}

Mining under the slope of open-pit mine would inevitably lead to the redistribution of internal stress of the slope rock mass, causing the rock mass to move and destroy the original rock mass structure of the slope. The physical and mechanical properties of the rock mass are changed, which adversely affects the stability of the slope.

The loess overlying the slope is loose and porous. When the seepage passes through the Loess pores, the water flow is resisted by the soil particles, and the soil particles are subjected to the reaction force of water. Therefore, when there is seepage in the loess slope, the stability of the slope is particularly unfavorable.

Slope angle and slope height affect the stability of the slope. If the slope angle is same, the stability of the slope decreases as its height increases. This is because the self-weight stress of the slope gradually increases and the shear force generated by the slope sliding rises. If the height of the slope is fixed, larger the slope angle, worse is the stability of the slope. Meanwhile, in the upper Quaternary, loess and weathered residual layer are accumulated, and due to the poor mechanical properties and fragmentation characteristics of this layer, landslides also occur easily upon external disturbances (such as rainfall, earthquakes, etc.).

\section{Fuzzy comprehensive evaluation of slope stability}

Slope danger zoning and stability assessment comprise of a complex systematic project, and the nature of engineering varies with time and space. This complexity leads to an unclear boundary of slope stability and has a certain ambiguity. Common factors affecting slopes include rainfall, stratum minerals, geological structures, weathering of rock masses, earthquakes, and vibrational force during mineral mining. There are numerous and complex factors that affect the stability evaluation; however, the degree of influence of each factor is not the same and a certain correlation exists among these degrees. The use of a classic mathematical model to measure these degrees uniformly as well as the corresponding complex effects have proven challenging. All the factors can be integrated into one factor for evaluation purposes. For such complex system problems, the methods in fuzzy theory have been considered more reasonable for evaluation (Wang 2010).

\subsection{Selection of evaluation factors and data preparation}

Several complex factors affect the slope stability and all the influencing factors have different magnitude of effect. For example, internal factors such as the nature of rock and soil, geological structure, rock and soil structure, ground stress, etc. play a major role in controlling the slope stability. External factors such as hydrogeological conditions, weathering, earthquakes, man-made factors, etc., promote the deformation of the slope. Herein, according to the engineering geology and hydrogeological conditions of the Antaibao open-pit mine in combination with the actual conditions of open-pit mining and underground mining, following six indicators were selected as the evaluation factors to establish a fuzzy set:

$$
U=\left\{u_{1}, u_{2}, u_{3}, u_{4}, u_{5}, u_{6}\right\}
$$


where $\mathrm{U}$ is a set of six evaluation factors; $u_{1}, u_{2}, u_{3}, u_{4}, u_{5}$, and $u_{6}$ represent slope angle, slope height, rainfall intensity (annual average rainfall), comprehensive influence index of landslide characteristics, degree of geological structure influence, and well mining influence index, respectively.

These six evaluation factors did not have same effect on the slope stability. The instability and failure of the slope are the result of deformation of the slope to a certain extent. The initial stabilization stage leads to the appearance of cracks in the rock mass, with the gradual penetration of the sliding surface thereafter, and finally, the sliding surface is completely penetrated, resulting in instability and failure of the slope. The traditional slope stability is based on the limit state equations defined by the anti-sliding force and the sliding force to judge the slope stability. The slope is divided into three states: instability, critical and stable. But the actual failure of the slope will have a certain transition process, and there is no good definition of the failure process between stability and instability. The fuzzy comprehensive evaluation method solves this problem very well. It divides the two processes of basic stability and basic instability between stability and instability. And the state of the slope can be fully evaluated. The degree of stability can be divided into four levels: stable, basically stable, basically unstable, and unstable (Liu et al. 2013). The evaluation set was consequently established:

$$
\text { . } V=\left\{v_{1}, v_{2}, v_{3}, v_{4}\right\}
$$

where $v_{1}, v_{2}, v_{3}$, and $v_{4}$ represent stable slope, basically stable slope, basically unstable slope, and unstable slope

The values of $v_{1}, v_{2}, v_{3}$, and $v_{4}$ are the base values in the stable level corresponding to each indicator factor. The base value and the evaluation criteria of each influencing factor are presented in Table 1, while the evaluation methods of discrete indicators are presented in Table 2.

The six evaluation factors are divided into four levels: $v_{1}, v_{2}, v_{3}$, and $v_{4}$ according to Tables 1 and 2. On the basis of the four levels, the base values can be used to obtain the comprehensive evaluation criteria for slope stability:

$$
V=\left(\begin{array}{cccc}
15 & 22.5 & 35 & 50 \\
100 & 150 & 250 & 300 \\
1 & 2 & 3 & 4 \\
1 & 2 & 3 & 4 \\
1 & 2 & 3 & 4 \\
0.25 & 0.375 & 0.625 & 0.75
\end{array}\right)
$$

\subsection{Weight determination}

As the influence of each single evaluation index (or evaluation element) on the stability of the slope is different, different corresponding weights exist. The weight calculation equation is:

$$
W_{i}=\frac{C_{i}}{S_{i}}
$$

where $C_{i}$ is the measured value of various indicators, and $S_{i}$ is a representative value of each index level. 


$$
S_{i}=\frac{1}{j}\left(S_{1}+S_{2}+\cdots+S_{j}\right)
$$

(Note: If an indicator is opposite to other indicators, a larger value indicates a smaller effect on slope stability. In this case, reciprocal must be considered for weight calculation)

$$
W_{i}=\frac{S_{i}}{C_{i}}\left(C_{i} \neq 0\right)
$$

To perform fuzzy operations, the individual weight values must also be normalized:

$$
\bar{W}_{i}=\frac{C_{i} / S_{i}}{\sum_{i=1}^{n} C_{i} / S_{i}} \longrightarrow \bar{W}_{i}=\frac{W_{i}}{\sum_{i=1}^{n} W_{i}}
$$

\subsection{Determination of membership function by evaluation factors}

Considering the previous works on membership function in the evaluation of fuzzy mathematics, the influencing factors that affect the slope stability of the Antaibao open-pit mine were obtained (slope height, slope angle, rainfall intensity, landslide characteristics comprehensive influence index, geological structure influence degree, and well mining influence index). The corresponding membership functions of the four stability levels were roughly triangular and trapezoidal functions (Zhang et al. 2010). The comprehensive evaluation of the slope stability quality of Antaibao surface mine in Shanxi Province was: $V_{1}$ stable, $V_{2}$ basically stable, $V_{3}$ basically unstable, and $V_{4}$ unstable. The membership functions of each evaluation factor relative to the four stable levels were calculated according to the ladder and triangular distributions (as presented in Fig. 3). The calculation equations are:

$$
\begin{gathered}
V_{1 i}=\left\{\begin{array}{l}
1\left(x \leq a_{1}\right) \\
\frac{a_{2}-x}{a_{2}-a_{1}}\left(a_{1} \leq x \leq a_{2}\right) \\
0\left(x \geq a_{2}\right)
\end{array}\right. \\
V_{2 i}=\left\{\begin{array}{l}
0\left(x \geq a_{3}, x \leq a_{1}\right) \\
\frac{x-a_{1}}{a_{2}-a_{1}}\left(a_{1} \leq x \leq a_{2}\right) \\
\frac{a_{3}-x}{a_{3}-a_{2}}\left(a_{2} \leq x \leq a_{3}\right)
\end{array}\right.
\end{gathered}
$$




$$
\begin{gathered}
V_{3 i}=\left\{\begin{array}{l}
0\left(x \geq a_{4}, x \leq a_{2}\right) \\
\frac{x-a_{2}}{a_{3}-a_{2}}\left(a_{2} \leq x \leq a_{3}\right) \\
\frac{a_{4}-x}{a_{4}-a_{3}}\left(a_{3} \leq x \leq a_{4}\right)
\end{array}\right. \\
V_{4 i}=\left\{\begin{array}{l}
0\left(x \leq a_{3}\right) \\
\frac{x-a_{3}}{a_{4}-a_{3}}\left(a_{3} \leq x \leq a_{4}\right) \\
1\left(x \geq a_{4}\right)
\end{array}\right.
\end{gathered}
$$

where the measured values $a_{i}(i=1,2,3,4)$ of the evaluated group are I, II, III, and IV evaluation standard values, respectively. $V_{1 i}, V_{2 i}, V_{3 i}$ and $V_{4 i}$ are membership functions.

\subsection{Comprehensive Evaluation Division Results}

Following the membership function determination, the six fuzzy membership degrees of each of the six stable factors of the fuzzy set $\{\mathrm{V} 1, \mathrm{~V} 2, \mathrm{~V} 3, \mathrm{~V} 4\}$ were calculated. Based on these four membership degrees, the membership was formed by A $(6 \times 4)$ order fuzzy relation matrix composed of degrees.

As an example, a unit was arbitrarily selected and its six factor scores were 40, 200, 3, 3, 3, and 0.3. Each number was substituted for the above membership function to be calculated. The A $(6 \times 4)$ order matrix was obtained as:

$$
R=\left(\begin{array}{cccc}
0 & 0 & 0.67 & 0.33 \\
0 & 0.5 & 0.5 & 0 \\
0 & 0 & 1 & 0 \\
0 & 0 & 1 & 0 \\
0 & 0 & 1 & 0 \\
0.6 & 0.4 & 0 & 0
\end{array}\right)
$$

where each row represents the membership of each factor to the four slope stability zones. Substituting the fuzzy relationship matrix $R$ and the weight distribution matrix $A$ into $B=A x R$ equation, the fuzzy comprehensive evaluation result of the unit to be evaluated in the unit $(10,8)$ was obtained.

$$
B=A x R=[0.18,0.24,0.32,0.26]
$$

According to the aforementioned fuzzy mathematical comprehensive evaluation method for the unit $(10,8)$ area to be evaluated, the 250 units to be evaluated in the entire Antaibao open-pit mine were evaluated individually. Consequently, the evaluation of entire Antaibao open-pit mine slope was completed and the results are presented in Fig. 4.

Unstable area: The unstable area is presented in red in Fig. 4. The stability quality grade of this part of the slope is $V_{3}$. It was mainly distributed at the entrance of the northern mining and the goaf. Herein, the slope angle and height of the slope were large, which were affected by the underground mining and underground goaf. High amounts of gravel and loose loess existed and with heavy rainfall, danger of landslides occurred. Another portion of the unstable area was above the industrial plant, 
where high amount of cracks occurred on the ground surface due to the impact of rain erosion.

More unstable area: The more unstable area is presented in yellow part in Fig. 4, which was widely distributed, while mainly concentrated within the second and third steps of the north and west slope along the dump plant. The stability quality grade of this part of the slope is $\mathrm{V}_{4}$. The expansion of the slope caused new changes in the slope angle and slope height, gradually becoming unstable. Moreover, the excavation of dump plant produced mainly loose loess and neither reinforcement measures nor vegetation cover existed. With rainfall, instability and damage would occur easily because of erosion due to rain.

\section{Sensitivity analysis of factors affecting slope stability}

\subsection{Determination of slope potential slip surface}

As the slope of Antaibao open-pit mine was formed by the excavation of open-pit mines, the corresponding consolidation was historically completed. The boundary of the rock and soil weathering zone was not apparent. Consequently, the potential sliding surface of the slope must be first determined. The slope of the west side of the Antaibao open-pit mine was relatively gentle, and the second and third steps were Quaternary accumulated loess and weathered layers, which belong to the loose structure and are relatively uniform. Therefore, the type of slope failure of the west slope belongs to the arc sliding mode. According to the engineering geological survey drilling data and slope anchor cable drilling construction, a structural fracture zone existed at a depth of approximately $60 \mathrm{~m}$, perpendicularly to the slope surface, while the rock and soil were in the form of broken blocks. Then, automatic search technology (simplified Bishop method) was used to determine the location of potential sliding surfaces. Therefore, as presented in Fig. 5, a potential sliding arc was formed through the crest and slope foot along the fracture zone.

\subsection{Sensitivity analysis of slope stability factors}

\subsubsection{MSARMA method}

The MSARMA method is an improved version of the SARMA method, and is one of the limit equilibrium analysis methods. The difference from SARMA method is that there are lesser basic assumptions, wider applications, stricter mathematical derivation, and higher precision. Also, this method considers the combined effects of various unfavorable factors and can be used for slope engineering design and optimization. It is especially suitable for the stability calculations and reinforcement design of high rock slopes. The MSARMA method not only considers the non-homogeneous boundary conditions of the slope, but also considers the stability of the slope under the load and reinforcement of the slope (Morgenstern 1965; Spencer 1967; SARMA 1973; Yang et al.2017; Zhu et al.2018).

\subsubsection{Model establishment}

According to the determined potential slip surface and slope surface shape, two representative sections at the western slope were selected to establish the calculation models, as presented in Figs. 6 and 7.

MSARMA was utilized for slope stability analysis. The safety factor under various conditions are presented in Tables 4 and 5.

\subsubsection{Sensitivity Analysis of Slope Steady State to Impact Factors}

The sensitivity analysis of slope drainage rate (Dr), bulk density of the slope soil, bottom sliding 
surface $\mathrm{cB}, \varphi \mathrm{B}$ value, side sliding surface cs, $\varphi s$ value, and seismic coefficient $\mathrm{kc}$ were performed. The analysis results are as follows. The slope drainage rate and earthquake were two extremely active environmental forces that affected the slope stability and constitute the inducing factors of slope deformation and failure. For instance, compared to dry slopes and saturated slopes, the stability coefficient was significantly improved (Fig. 8, Fig. 9); Under VII Richter earthquake, the stability factor of the slope was lower than without any earthquake, while the corresponding stability factor decreased rapidly as the seismic coefficient increased (Figs. 10 and 11).

\section{Numerical simulation analysis of northwest slope stability}

The sensitivity analysis of the influence factors of potential sliding surface of the west side was performed according to the MSARMA method, with drainage rate and bottom sliding surface as the sensitivity factors. FLAC3D software was used to perform numerical analysis of the stability under natural conditions, seepage conditions, and earthquakes on the northwest slope.

\subsection{Slope stability analysis under natural conditions}

(1) Model development

The slope grid element obtained through FLAC3D with ANSYS is presented in Fig. 12. The entire model consisted of tetrahedrons with 121,487 units and 25,391 nodes. The model had a length of $1064.219 \mathrm{~m}$ and a width of $785 \mathrm{~m}$. The elevation of the highest point on the surface was $1450 \mathrm{~m}$ and the elevation of the lowest point was $1230 \mathrm{~m}$. The rock and soil parameters of each strata are shown in the Table 7.

(2) Formation of groundwater surface

As it was difficult to directly generate the groundwater level in FLAC3D that can conform to the complex spatial geometry described in the survey data, herein, the characteristics of the interface elements in FLAC3D that can automatically attach to the model surface within a specified range were employed to generate the groundwater level, and the process was continued. The fluid parameters of the formation are shown in the Table 8 .

In ANSYS, a regular geometric entity that was slightly larger than the existing engineering geological model was first generated.

As per the limited number of points on the groundwater level provided by the survey data, the groundwater level was generated through ASKIN in a point-to-line and surface-to-bottom manner within ANSYS.

The groundwater surface generated by ASKIN was used to cut regular geometric entities to obtain the groundwater surface as well as the corresponding lower geometric entities, while the mesh was divided to derive the grid data.

The grid data of the entities below the groundwater level were imported into FLAC3D, while the interface unit could automatically rely on the surface characteristics of the grid unit to generate the interface unit consistent with the spatial form of the groundwater level.

As the grid data were used as an auxiliary unit, the interface element nodes were traversed in FISH language, to generate a water level surface that can attach to the surface of the underwater part while generating the hydrostatic pressure.

The grid data of engineering geological model were imported and grouped according to actual material properties. 
The mesh model that was previously imported as the water level surface and the hydrostatic pressure carrier was deleted. The groundwater level surface and the hydrostatic pressure existed due to the new mesh model carrier. The first three steps of the entire process were completed in ANSYS, while the last four steps were completed in FLAC3D. The groundwater level generated through the latter method along with its position in the model are presented in Fig. 13. Also, the simultaneously generated hydrostatic pressure cloud map is presented in Fig. 14.

(3) Constraints

For the calculation constitutive model, the Mohr-Coulomb model was utilized. Except for the free boundary of the slope, the model bottom was a fixed constraint boundary, while the model was surrounded by a one-way boundary. In the initial conditions, only the initial stress field and hydrostatic pressure generated by the dead weight stress were considered.

(4) Calculations

For calculations, first, the hydrostatic pressure was generated, as per the method described above, whereas consequently the elastic constitutive model was selected. Also, the elastic solution was obtained under the constraints described above, wherein, only the action of gravity was considered. After the calculation reached equilibrium, the displacement field and velocity field were cleared to generate the initial stress field. Finally, the elastoplastic solution of the constitutive model to the Mohr-Coulomb model was performed until the system reached equilibrium.

As shown in Fig. 15 and 16, the northwest slope sustained certain displacements under natural conditions. The maximum displacement in the $\mathrm{X}$ direction occurred in the west slope $(30 \mathrm{~cm})$, while the maximum displacement in the $\mathrm{Y}$ direction occurred in the north slope $(41 \mathrm{~cm})$.

Fig. 17 and 18 present the displacement vector diagram and displacement cloud diagram of the typical section and $\mathrm{y}=200 \mathrm{~m}$ section, respectively. As per the displacement vector diagram, the displacement vector of the upper part of the slope was vertically downward, which represents settlement. The displacement vector in the middle was almost parallel to the slope surface and appeared as shear. The lower displacement vector appeared as cut out at the asymptotic slope toe. Correspondingly, the displacement profile was distributed vertically within the middle and upper parts of the slope, without intersecting the slope surface, while the inflection point was further from the slope surface. In the lower part, the displacement profile was almost parallel to the slope bottom, turning upwards near the slope surface. These phenomena indicate that the slope potential failure was dominated by the shallow arc shear failure.

Fig. 19 presents the chart of maximum principal stress of the slope under natural conditions. The contours of the principal stresses were smooth and almost parallel to each other, with few abrupt changes. Only inconspicuous stress concentration occurred within the area near the interface of the rock and soil body along with the slope foot effect. This phenomenon indicates that the overall geometry of the concave slope effectively reduced the slope stress concentration. Therefore, it can be concluded that the interface of the rock and the toe of the slope were prone to instability, and the damage of these places should be considered when supporting the slope.

\subsection{Slope stability analysis under seepage conditions}

Loess is the overlying soil layer of the Antaibao open-pit mine, which was loose and porous. When the seepage penetrated its pores, the soil particles were in contact with the water flow. Water flow was resisted by the soil particles, while the soil particles reacted with water. Therefore, when there 
was seepage in the loess slope, the stability of the slope was particularly unfavorable. In this section, the slope stability of the northwest slope is analyzed when the seepage occurred under rainfall conditions.

Fig. 20 presents the seepage field of the northwest slope, and as shown, the direction of the seepage field was downwards to the slope. Therefore, when seepage occurred, the slope soil moved downwards to the slope. The force was extremely detrimental to the stability of the slope.

As shown in Fig. 21 and 22, the maximum displacements of the northwest slope in the $\mathrm{X}$ and $\mathrm{Y}$ directions under the seepage conditions were $45 \mathrm{~cm}$ and $70 \mathrm{~cm}$, respectively, compared to $30 \mathrm{~cm}$ and $41 \mathrm{~cm}$ under natural conditions, demonstrating high increase, especially the increase in the north slope reaching $29 \mathrm{~cm}$. Also, when concentrated heavy rainfall occurred, the slope stability was highly reduced. From the above numerical analysis, it can be seen that rainfall is the main factor inducing landslide instability. Combining the site conditions, adopt interception and drainage measures to effectively prevent rainfall from infiltration of surface water and reduce the impact of groundwater activities Therefore, the purpose of increasing the stability of the landslide can be achieved.

\subsection{Slope stability analysis under earthquake}

Slope vibration damage effect constitutes the slope damage directly caused by the seismic force, which generally includes horizontal sliding or shaking of the slope as well as resonance. This is the main vibration in seismic effects. During an earthquake, due to the propagation of seismic waves on the surface of the earth crust and ground, there is instantaneous oscillation and shaking, while the soil layers of the slope vibrate accordingly. When the structural vibration exceeds its allowable limit, it causes damage, constituting an inertial force role. To simplify the calculations, herein, the effect of only horizontal seismic force was considered. Moreover, seismic acceleration was applied in one direction only at a time. Seismic force is caused by the acceleration of harmonic waves in the crustal rock mass during seismic wave propagation. If the mass point performs a simple harmonic acceleration towards the horizontal direction, its maximum horizontal acceleration is deduced, as presented in equation (14):

$$
a_{\max }= \pm A\left(\frac{2 \pi}{T}\right)^{2}
$$

where $a_{\max }$ is the maximum horizontal acceleration, $T$ is the vibration cycle, and $A$ is the amplitude

Under this condition of maximum horizontal acceleration of the rock mass point, the horizontal inertial force on the upper slope of the rock mass reached maximum. Considering this phenomenon, the acceleration waveform at the bottom of the input model was produced and is presented in Fig. 23

Fig. 24 presents the X-direction displacement time-history curve of the western slope monitoring point, where the red line represents the X-direction displacement curve of the top point and the black line represents the X-direction displacement curve of the bottom point. As shown, both the top and bottom points increased with time. Also, the displacement increased, while the bottom point was less displaced due to the constraint of the surrounding soil. Furthermore, the top point was present due to the empty surface; therefore, the displacement was high.

Fig. 25 presents the Y-direction displacement time-history curve of the bottom and top points of the north slope. The red curve represented the displacement curve of the top point and the black curve 
represented the displacement curve of the bottom point. It could be observed that the displacement directions of the bottom and top points were both negative directions of $\mathrm{Y}$, facing the air-facing surface. The displacement was also higher at the top point and lower at the bottom point.

\section{Conclusions}

This paper determines several factors that are critical to slope stability based on the high steep analysis of engineering geological conditions. Then, based on division, a key analysis was performed for the dangerous area, combining the physical and mechanical characteristics of the rock and soil in the dangerous area and the actual working conditions. The MSARMA method was used to determine the sensitive factors of the slope stability, and then, FLAC was employed to quantitatively analyze the impact of the sensitive factors on the sensitive factors. The main conclusions are drawn as follows:

(1) According to the composition and structural characteristics of the slope rock mass, six typical catastrophic factors were selected among many influencing factors. Based on the fuzzy mathematical comprehensive evaluation principle, the stability of the high and steep sides within the multi-factor influence region was comprehensively evaluated, while the spatial divisions for the unstable region and more unstable region were determined.

(2) Based on the fuzzy comprehensive evaluation results, the entrance and mined-out areas of the north slope were unstable areas. Once rainfall occurs, danger of landslides exists. Due to the continuous expansion of the second and third steps of the north and west slope, new changes happened in the slope angle and slope height, which led them to become gradually unstable.

(3) The potential sliding surface of the slope in the unstable zone of the western slope was used in the calculation model. The MSARMA method was utilized to calculate the sensitivity of various factors affecting the slope stability. Through sensitivity analysis, it can be concluded that seepage and earthquake were two factors that had higher impact on the Antaibao surface mine slope stability.

(4) Flac3D was used to build a three-dimensional model of the northwest slope, as well as to calculate the $\mathrm{X}$ and $\mathrm{Y}$ displacements of the northwest slope under natural, seepage, and vibrational conditions. According to the analysis, the displacement of the northwest slope was low under natural conditions, but the displacement exceeded the allowable value for the stability of the slope under seepage and vibrational conditions. The displacement of the northwest slope in the $\mathrm{X}$ and $\mathrm{Y}$ directions under natural condition was small, but the displacements under seepage condition and vibrational condition were large. And the displacement in the $\mathrm{Y}$ direction under vibrational condition moved to the empty surface of the slope. Therefore, under seepage and vibrational conditions, the slope could easily become unstable.

\section{References}

Byea AR, Bellb FG (2001) Stability assessment and slope design at Sandsloot open pit, South Africa. Int J Rock Mech Min 38(3):449-466.

Chen X, Zhang L, Chen L et al (2018) Slope stability analysis based on the Coupled Eulerian-Lagrangian finite element method. Bull Eng Geol Environ (2).

Cui P, Zhu YY, Han Y S et al (2009) The 12 May Wenchuan earthquake-induced landslide lakes: distribution and preliminary risk evaluation. Landslides 6(3):209-223.

Cascini L (2008) Applicability of landslide susceptibility and hazard zoning at different scales. Eng Geol 102(3-4):164-177. 
Chen JT, Zhao JH, Zhang SC, et al. (2020) An experimental and analytical research on the evolution of mining cracks in deep floor rock mass. Pure Appl Geophys, 2020. https://doi.org/10.1007/s00024-020-02550-9.

Du Y, Sheng Q, Fu X et al (2019) Risk evaluation of colluvial cutting slope based on fuzzy analytic hierarchy process and multilevel fuzzy comprehensive evaluation. J Intell Fuzzy Syst 37(3):1-19.

Ersoz T, Topal T (2018) Assessment of rock slope stability with the effects of weathering and excavation by comparing deterministic methods and slope stability probability classification (SSPC). Environ Earth Sci 77(14):1-18.

Fellenius W (1957) Static calculation of soil stability. China Water

Feng G, Wang XC, Wang M, et al. (2020) Experimental investigation of thermal cycling effect on fracture characteristics of granite in a geothermal-energy reservoir. Eng Fract Mech, 235: 1-16. article ID: 107180.

He MC, Zhang JF, Heng CY et al (2004) Research on critical inclination of cut slope of expansive soft rock in Yanbian region. J LiaoNing Tech Univ 01:55-56

Hu SC, Tan YL, Zhou H, et al. (2020) Anisotropic modeling of layered rocks incorporating planes of weakness and volumetric stress. Energy Sci Eng, 8(3): 789-803.

Jaiswal P, Van WC J, Jetten V (2011) Quantitative estimation of landslide risk from rapid debris slides on natural slopes in the Nilgiri hills, India. Nat Hazards Earth Syst Sci 11(6):1723-1743

Kundu J, Sarkar K, Singh PK et al (2018) Deterministic and Probabilistic Stability Analysis of Soil Slope - A Case Study. J Geol Soc India 91(4):418-424.

Liu S, Su Z, Li M et al (2020) Slope stability analysis using elastic finite element stress fields. Eng Geol 273:105673

Liu DK, Gu ZL, Liang RX, et al. (2020) Impacts of pore-throat system on fractal characterization of tight sandstones, Geofluids, 2020(9): 1-17. Article ID, 4941501.

Li SJ, Feng XT, Zhang XW et al (2005) Study on development and application of three-dimensional intelligent information system for slope safety assessment. Chin J Rock Mech Eng 19:21-28

Liu HL, Lu HQ, Li HW et al (2013) Application of new method based on fuzzy comprehensive assessment for stability of landslide. J PLA Univ Sci and Technol 14 (1)

Muceku Y, Jaupaj O (2018) Landslide Hazard Zonation Along Milot-Kukes Motorway, Albania. Period Polytech Civ Eng 62.

Ma CL, Zhu M (2008) Application of Finite Difference Method FLAC in Slope Stability Analysis. Chin Min Eng 37(5): 19-22

Meng H (2008) Comparative study of rock slope stability analysis based on slope/w and fuzzy evaluation .Express Inf Min Ind 9:23-26

Morgenstern NR, Price VE (1965) The analysis of the stability of general slip surfaces. Geotech 18(1):92-93.

Pantelidis (2009) Rock slope stability assessment through rock mass classification systems. Int J Rock Mech Min $46(2): 315-325$

Qi C, Wu J, Liu J et al (2016) Assessment of complex rock slope stability at Xiari, southwestern China. Bull Eng Geol Environ 75(2):537-550.

Siddique T, Pradhan SP, Vishal V et al (2017) Stability assessment of Himalayan road cut slopes along National Highway 58, India. Environ Earth Sci 76(22).

Sarkar S, Pandit K, Sharma M et al(2018)Risk assessment and stability analysis of a recent landslide at Vishnuprayag on the Rishikesh - Badrinath highway, Uttarakhand, India. Curr Sci 114(7):1527-1533.

Saleem J, Ahmad SS, Butt A (2020) Hazard risk assessment of landslide-prone sub-Himalayan region by 
employing geospatial modeling approach. Nat Hazards 102.

Sassa K , Wang G , Fukuoka H et al(2004)Landslide risk evaluation and hazard zoning for rapid and long-travel landslides in urban development areas. Landslides 1(3):221-235.

Sun YK, Gu X(1980) Application of stereographic projection in rock engineering geomechanics.

Sun SF, Che YH(2008)Application of ABAQUS in slope stability analysis. ShanXi Archit 13:307-308.

Spencer E (1967) A method of analysis for stability of em-bankment using parallel inters slice force. Geotech 17:11-26.

SARMA SK(1973)Stability analysis of embankments and slope. J of Geotech engrg div asce 105(GT12):1511

Tang Y, Che A, Cao Y et al (2020) Risk assessment of seismic landslides based on analysis of historical earthquake disaster characteristics. Bull Eng Geol Environ 79(5):2271-2284.

Tan XH, Hu XJ, Chu CF et al (2011) Fuzzy response surface method and its application in the reliability analysis of slope stability. J Univ Sci Technol Chin 41(03):233-237.

Whittall JR, Mcdougall S, Eberhardt E (2017) A risk-based methodology for establishing landslide exclusion zones in operating open pit mines. Int J Rock Mech Min Sci 100:100-107.

Wu Y, Zhang R, Le QL et al (2017) Based on the fuzzy mathematics and Geo-Studio comprehensive evaluation of the stability of the landslide. Sci Technol Eng 17(23):168-173.

Wang MX (2010) Application of fuzzy mathematics to slope stability analysis. Rock Soil Mech 31(09)

Wang X, Liu C, Chen S, et al. (2020a) Impact of coal sector's de-capacity policy on coal price. Appl Energ, $265: 114802$

Wang CX, Shen BT, Chen JT, et al. (2020b) Compression characteristics of filling gangue and simulation of mining with gangue backfilling: An experimental investigation. Geomech Eng, 2020, 20(6):485-495.

Wan H, Zhang YH, Zhu ZQ (2015) An improved fuzzy method for evaluating stability of highway slopes. Rock Soil Mech 36(11):3337-3344

Yao AJ, He MC (2002) Application of msarma method in the probability analysis of slope stability. Chin J Rock Mech Eng 12:1839-1842.

Yang XJ, Hou DG, Wang JM et al (2017) Study on the stability and remote real-time monitoring for high steep slope in Nanfen open pit iron mine. J Min Saf Eng 34(05):1000-1007.

Yao AJ (2001) Study of coupling analysis theory and method for slope engineering stability. Chin J Rock Mech Eng 03:418.

Zhang ZY, Wang ST, Wang LS (1981) Principles of engineering geological analysis. Geological Publishing House

Zhang SL, Zhang MX, Ji Sw et al (2015) Loose media slope stability evaluation based on fuzzy analysis. J Shanghai Jiaotong Univ 49(07):1035-1039

Zhu C, Tao ZG, Yang S et al (2018) V shaped gully method for controlling rockfall on high-steep slopes in China. Bull Eng Geol Environ 78(4):2731-2747

Zhu C, He MC, Karakus M, Cui XB, Tao ZG. (2020) Investigating toppling failure mechanism of anti-dip layered slope due to excavation by physical modelling. Rock Mech Rock Eng, 2020:1-20. Doi:10.1007/s00603-020-02207-y.

Zhang YH, Li HX, Sheng Q et al (2010) Study of stability gradation of highway rock slopes based on fuzzy comprehensive evaluation. Rock Soil Mech 31(10)

Zhang SL, Zhang MX, Ji SW et al (2015) Loose Media Slope Stability Evaluation Based on Fuzzy Analysis. J Shanghai Jiaotong Univ 49(07):1035-1039 


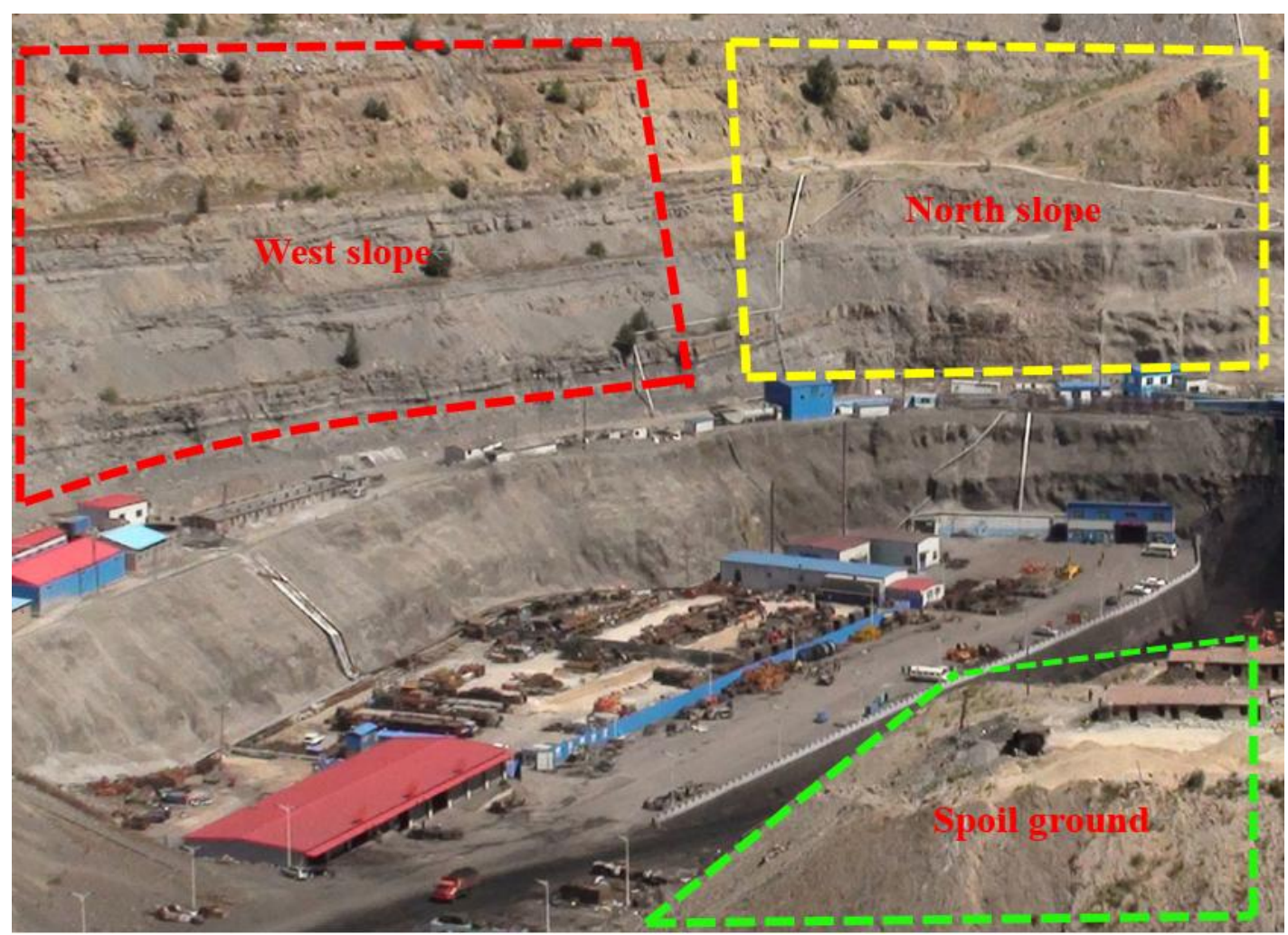

Fig. 1 Mining area panorama

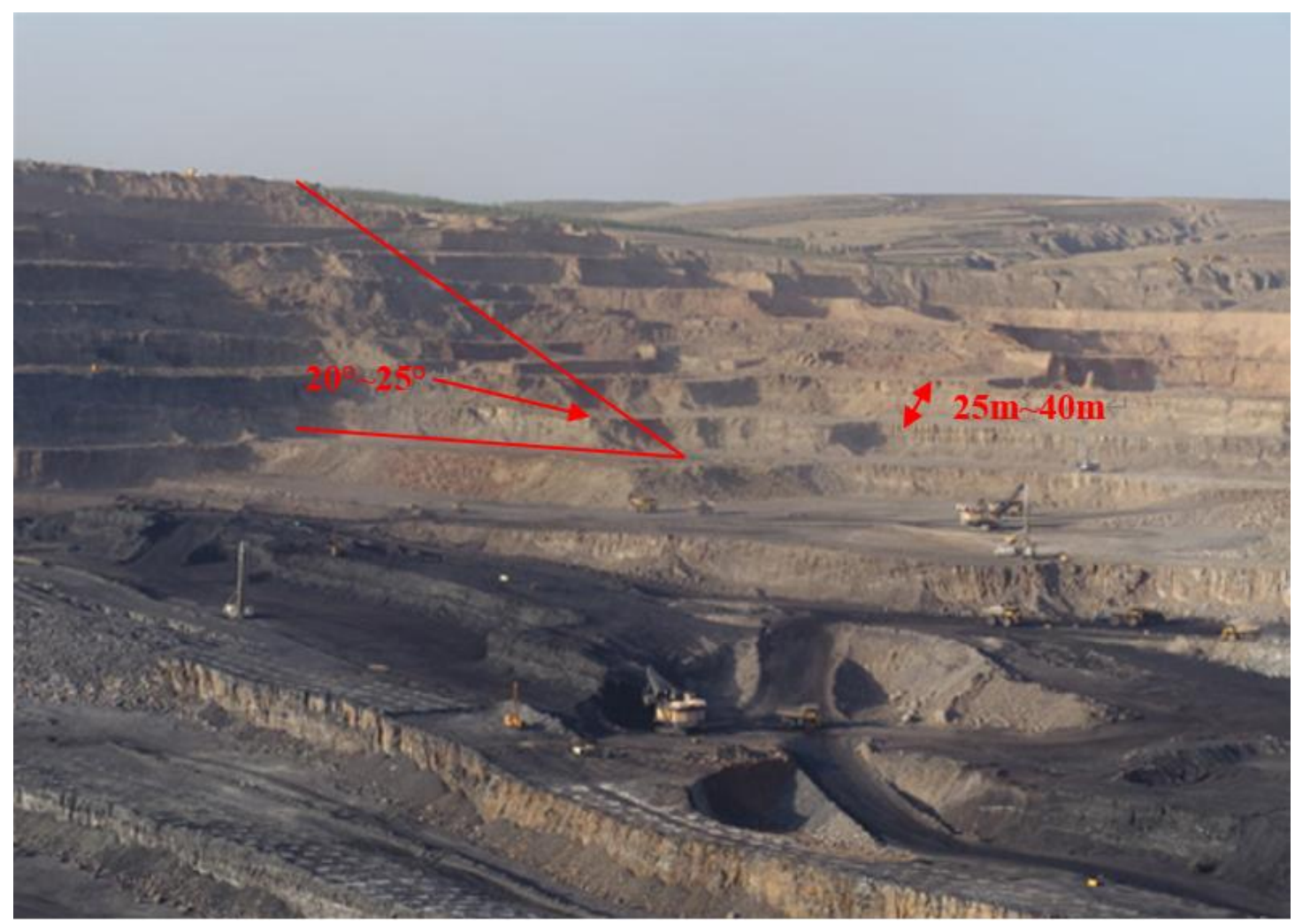

Fig. 2 The topography of mining area 


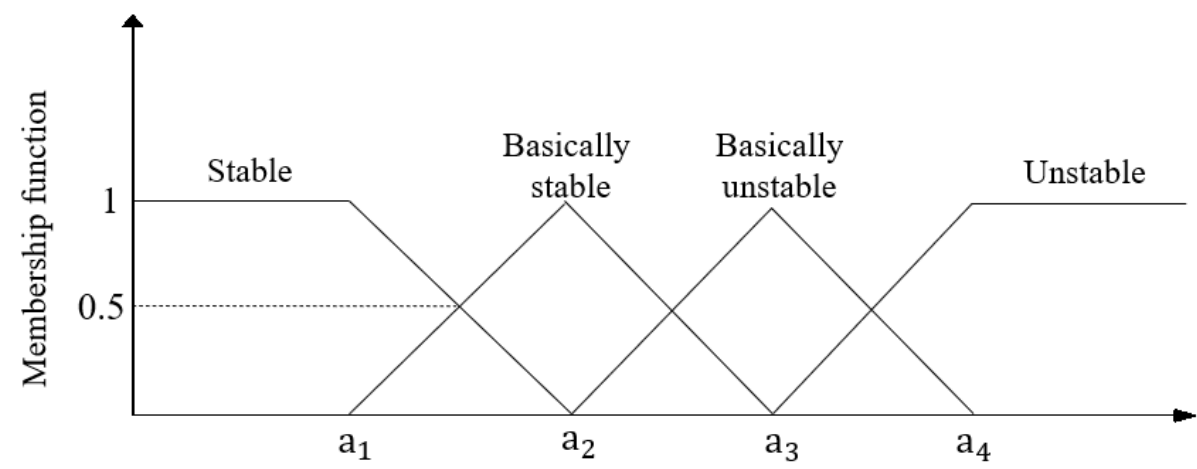

Fig. 3 Membership distribution function

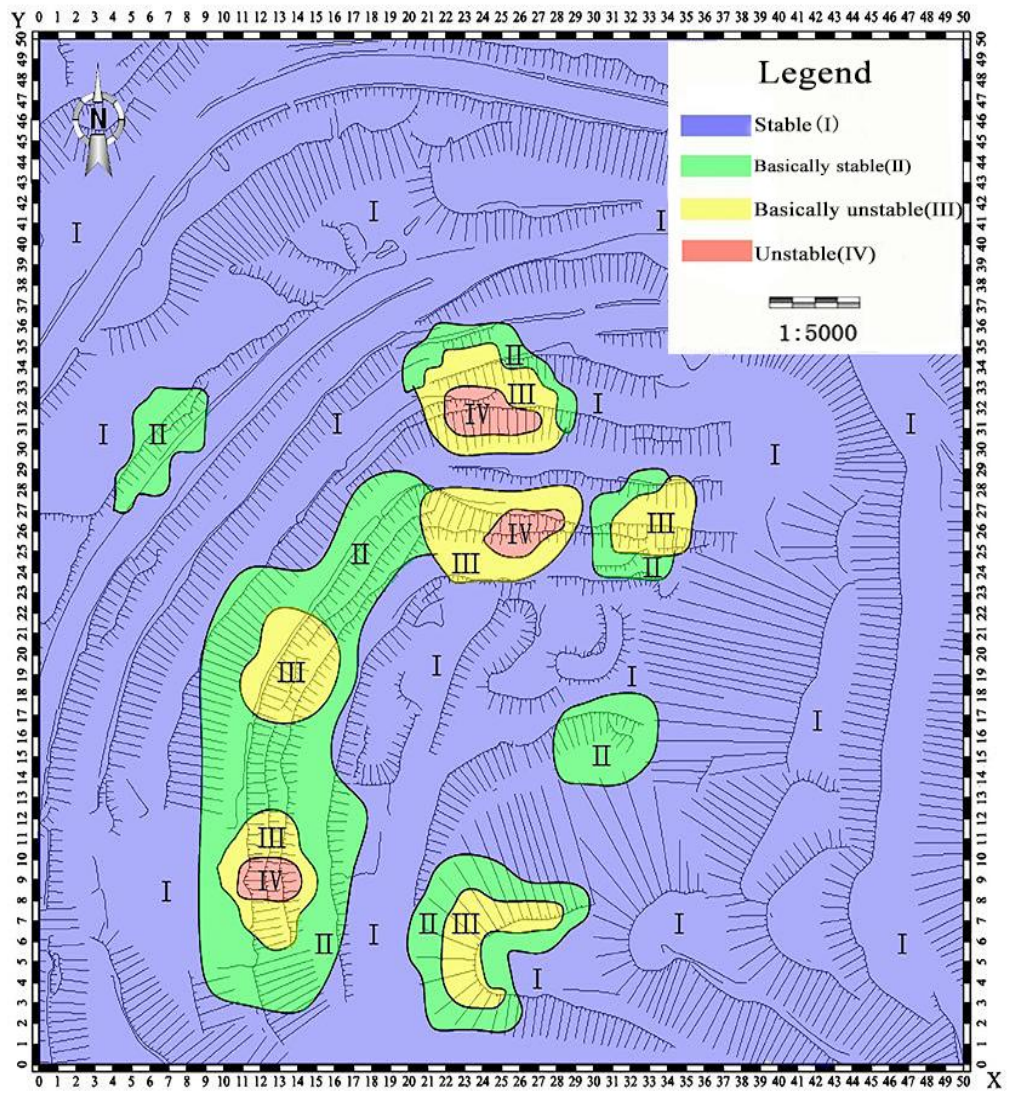

Fig. 4 Results cloud picture of the slope stability fuzzy comprehensive evaluation for Antaibao open pit mine 


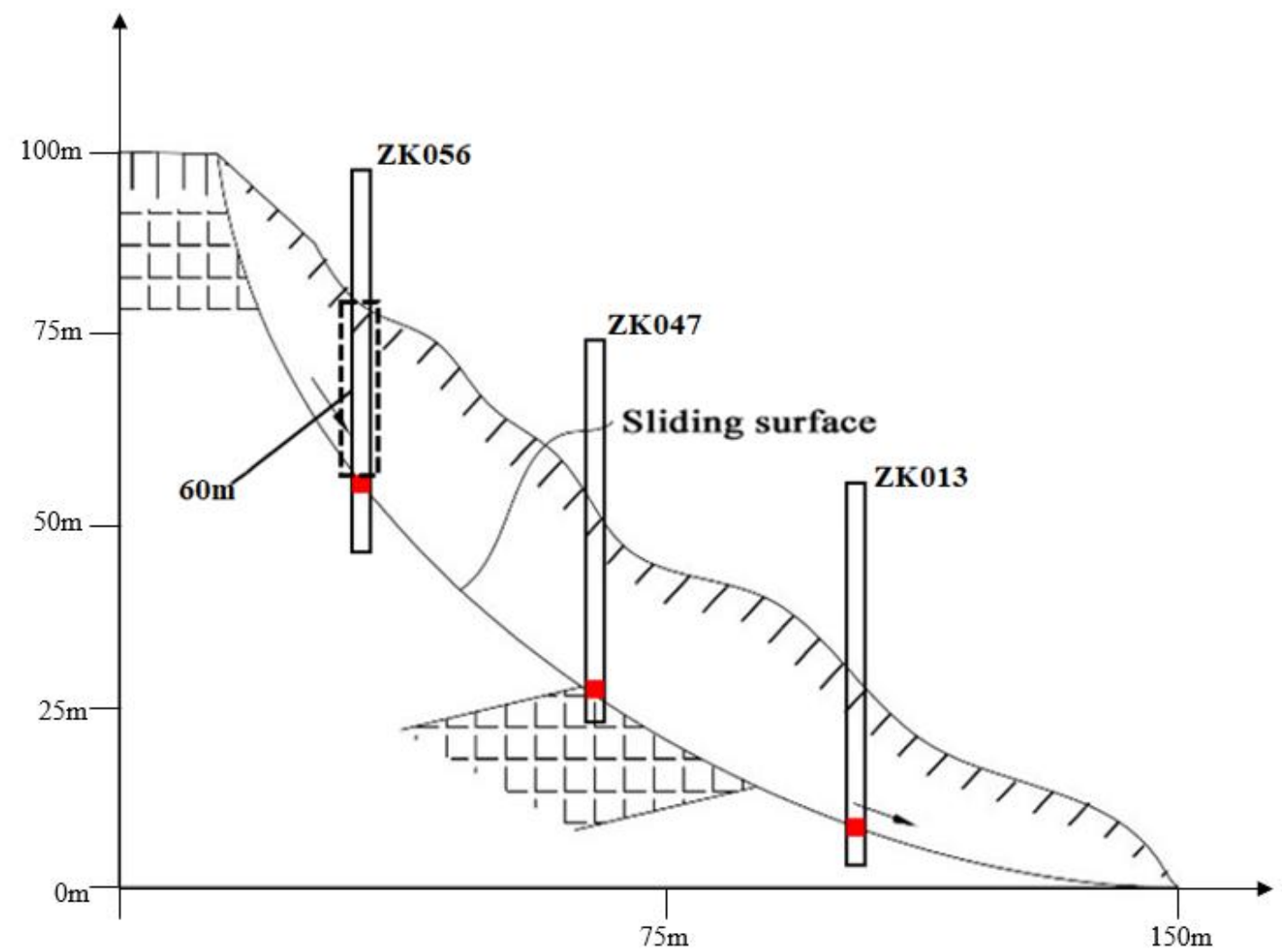

Fig. 5 Schematic diagram of sliding surface determination

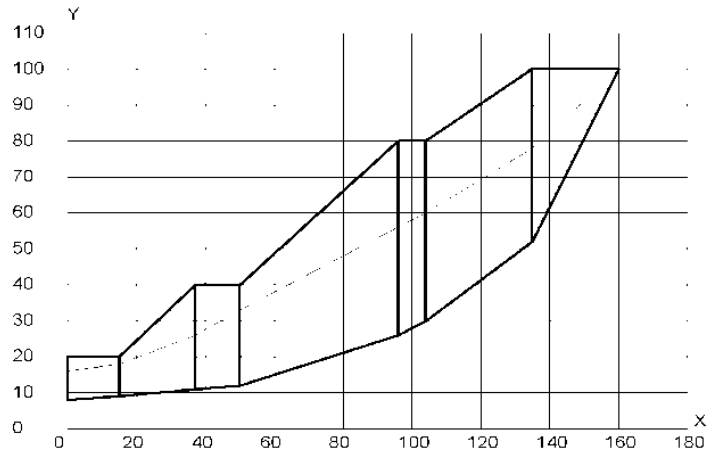

Fig. 6 MSARMA method computation

model of section 1

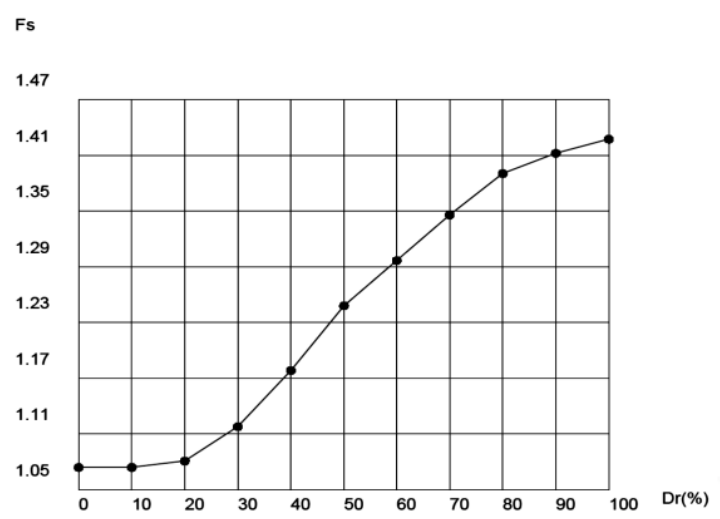

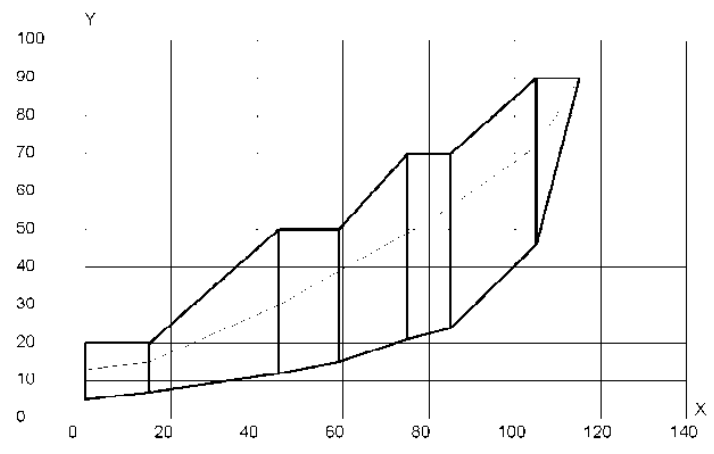

Fig.7 MSARMA method computation model of section 2

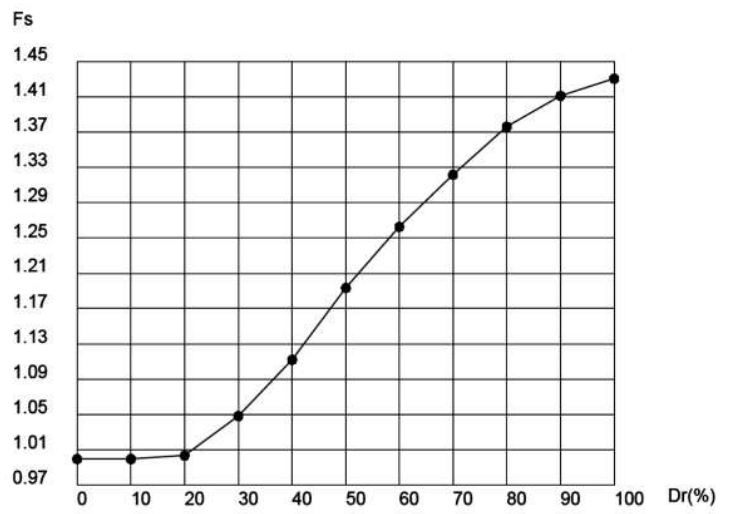


Fig. 8 Influence curve of driange rate on slope stability in section 1

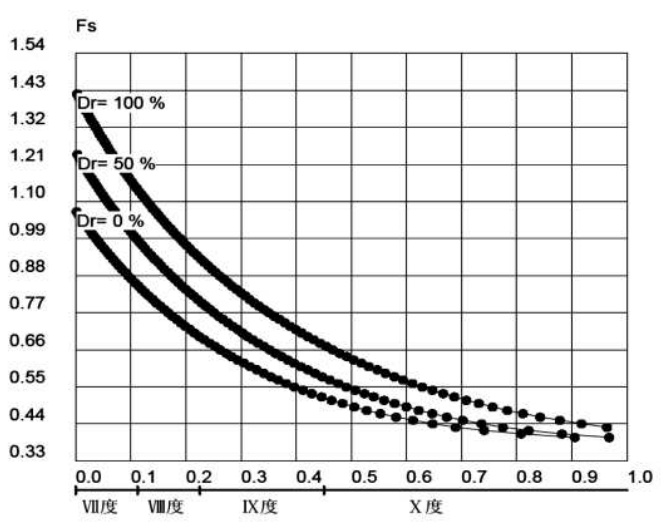

Fig. 10 Influence curve of seismic coefficient on slope stability in section 1
Fig. 9 Influence curve of driange rate on slope stability in section 2

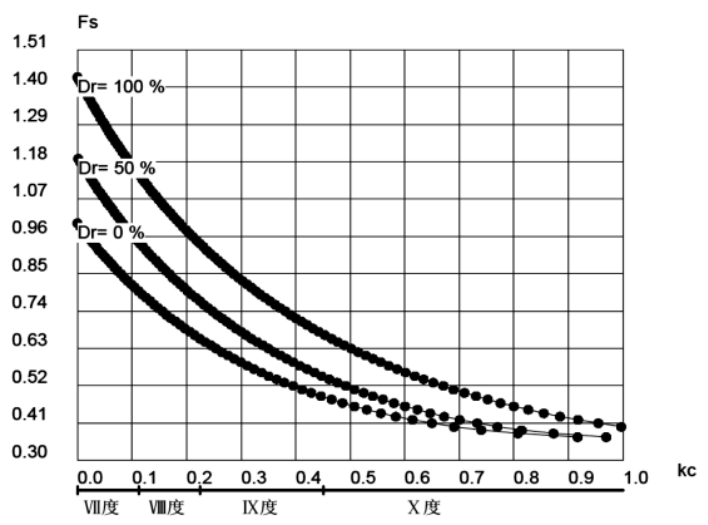

Fig. 11 Influence curve of seismic coefficient on slope stability in section 2

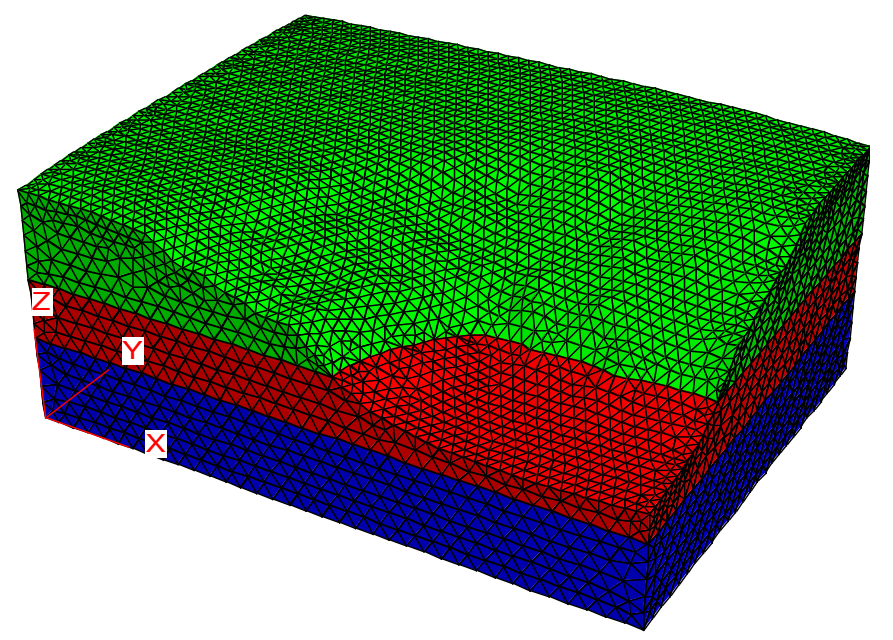

Block Group sandstone

weatheredsandstone loess

Fig. 12 Engineering geological model of northwest slope

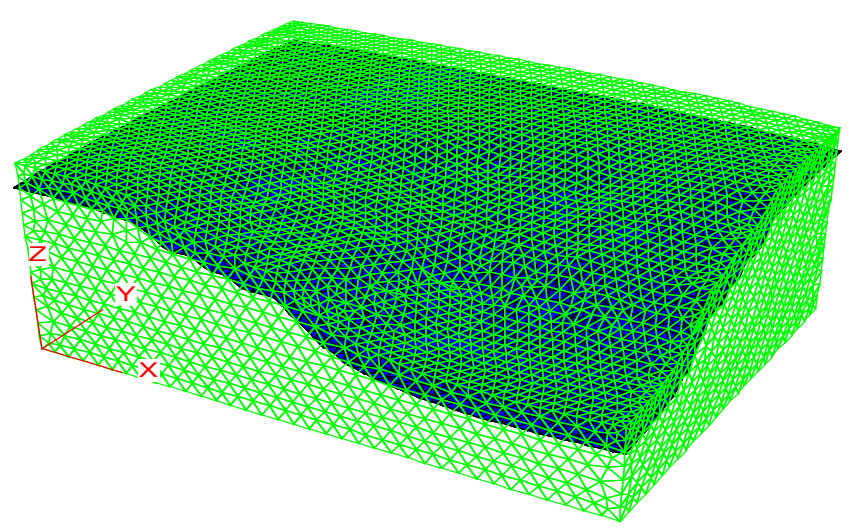

Water Surfaces

Sketch

Magfac $=0.000 \mathrm{e}+000$

Fig.13 Water surface position in model 


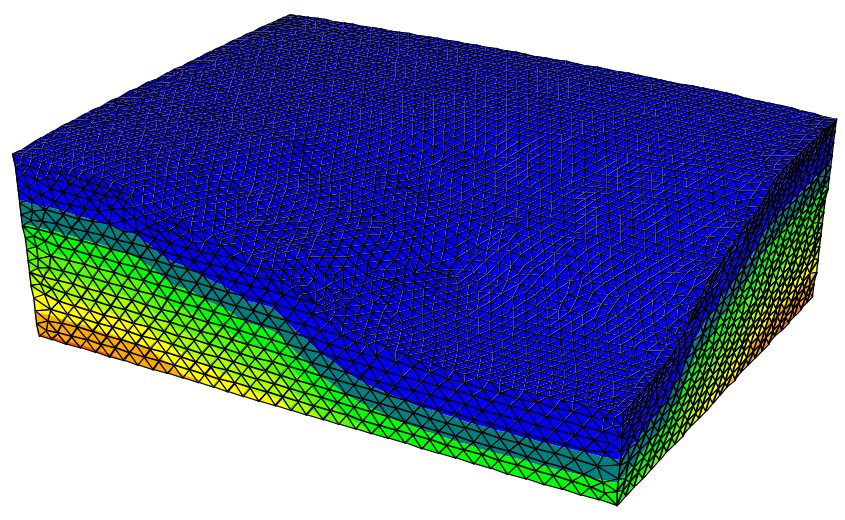

Contour of Pore Pressure Magfac $=0.000 \mathrm{e}+000$

$0.0000 \mathrm{e}+000$ to $5.0000 \mathrm{e}+005$ $5.0000 \mathrm{e}+005$ to $1.0000 \mathrm{e}+006$ $1.0000 \mathrm{e}+006$ to $1.5000 \mathrm{e}+006$ $1.5000 \mathrm{e}+006$ to $2.0000 \mathrm{e}+006$ 2.0000 e 006 to $2.5000 \mathrm{e}+006$ 2.5000e+006 to $3.0000 \mathrm{e}+006$ $3.0000 \mathrm{e}+006$ to $3.5000 \mathrm{e}+006$
$3.5000 \mathrm{e}+006$ to $3.5681 \mathrm{e}+006$ nterval $=5.0 \mathrm{e}+005$

Fig. 14 Contour of pore pressure

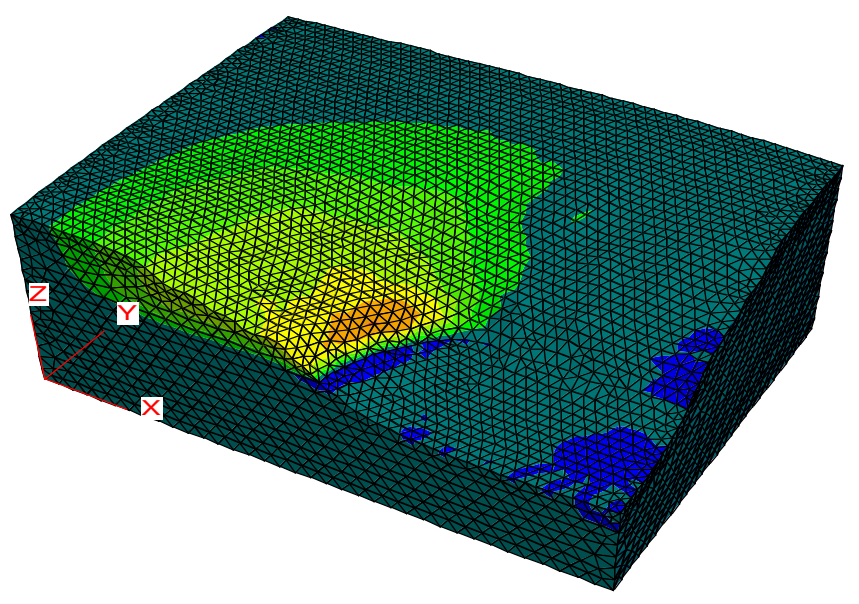

Contour of X-Displacement Magfac $=0.000 \mathrm{e}+000$

$-1.6341 \mathrm{e}-002$ to $0.0000 \mathrm{e}+000$ $0.0000 \mathrm{e}+000$ to $5.0000 \mathrm{e}-002$ $5.0000 \mathrm{e}-002$ to $1.0000 \mathrm{e}-001$ $1.0000 \mathrm{e}-001$ to $1.5000 \mathrm{e}-001$ $1.5000 \mathrm{e}-001$ to $2.0000 \mathrm{e}-001$ $2.0000 \mathrm{e}-001$ to $2.5000 \mathrm{e}-001$ $2.5000 \mathrm{e}-001$ to $3.0000 \mathrm{e}-001$ $3.0000 \mathrm{e}-001$ to $3.0575 \mathrm{e}-001$ Interval $=5.0 \mathrm{e}-002$

Fig. 15 Contour of X-displacement of northwest slope under natural condition

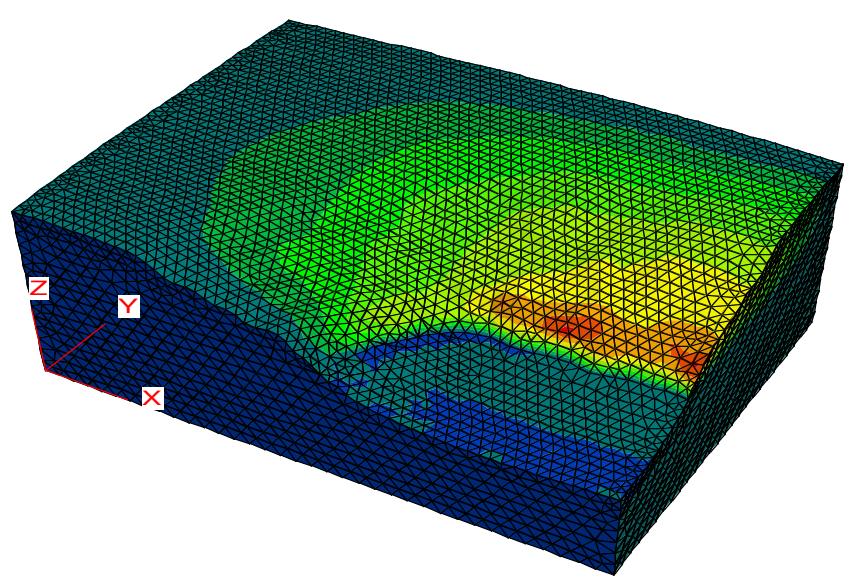

Contour of Y-Displacement Magfac $=0.000 \mathrm{e}+000$

$-4.1718 \mathrm{e}-001$ to $-4.0000 \mathrm{e}-001$ $-4.0000 \mathrm{e}-001$ to $-3.5000 \mathrm{e}-001$ $-3.5000 \mathrm{e}-001$ to $-3.0000 \mathrm{e}-001$ $-3.0000 \mathrm{e}-001$ to $-2.5000 \mathrm{e}-001$ $-2.5000 \mathrm{e}-001$ to $-2.0000 \mathrm{e}-001$ $-2.0000 \mathrm{e}-001$ to $-1.5000 \mathrm{e}-001$ $-1.5000 \mathrm{e}-001$ to $-1.0000 \mathrm{e}-001$ -1.0000 e-001 to -5.0000 e 002 $-5.0000 \mathrm{e}-002$ to $0.0000 \mathrm{e}+000$ -0.0000 e 000 to $2.4887 \mathrm{e}-003$ nterval $=5.0 \mathrm{e}-002$

Fig. 16 Contour of Y-displacement of northwest slope under natural condition 


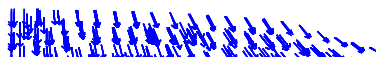

(14)

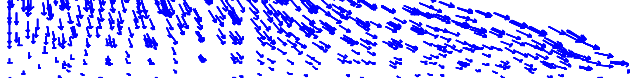

Displacement

Plane: on

Maximum $=3.422 \mathrm{e}-00$

Scale to $\operatorname{Max}=3.000 \mathrm{e}+000$

Fig. 17 Displacement vectors of $\mathrm{Y}=200 \mathrm{~m}$ section

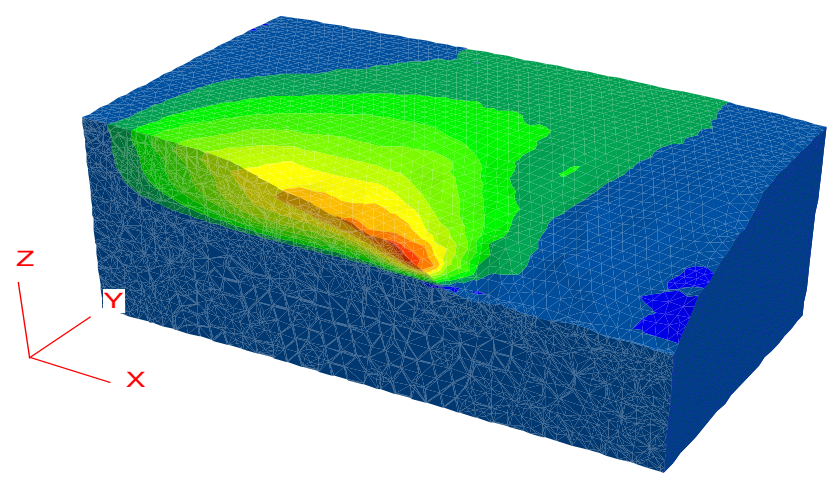

Fig. 18 Contour of $\mathrm{X}$-displacement of $\mathrm{Y}=200 \mathrm{~m}$ section and rear part

Contour of X-Displacement Plane: on behind

Magfac $=0.000 \mathrm{e}+000$

$-1.6341 \mathrm{e}-002$ to $0.0000 \mathrm{e}+000$

$0.0000 \mathrm{e}+000$ to $2.5000 \mathrm{e}-002$

$2.5000 \mathrm{e}-002$ to $5.0000 \mathrm{e}-002$

$5.0000 \mathrm{e}-002$ to $7.5000 \mathrm{e}-002$

$7.5000 \mathrm{e}-002$ to $1.0000 \mathrm{e}-001$

$1.0000 \mathrm{e}-001$ to $1.2500 \mathrm{e}-001$

1.2500001 t 1.25000001

1.500000101 .5500001

$1.5000 \mathrm{e} 001$ to $1.5000 \mathrm{e}-001$

$1.7500 \mathrm{e}-001$ to $2.0000 \mathrm{e}-001$

$2.0000 \mathrm{e}-001$ to $2.2500 \mathrm{e}-001$

$2.2500 \mathrm{e}-001$ to $2.4774 \mathrm{e}-001$

Interval $=2.5 \mathrm{e}-002$

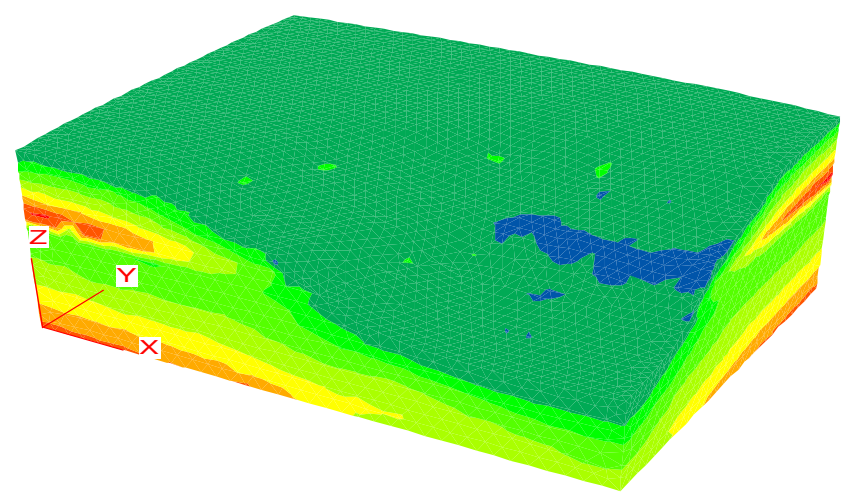

Fig. 19 Contour of maximum principal stress under natural condition

\section{Contour of SMax}

Magfac $=0.000 e+000$

Gradient Calculation

$-1.5051 e+006$ to $-1.4000 e+006$

$-1.4000 \mathrm{e}+006$ to $-1.2000 \mathrm{e}+006$

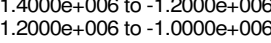

$-1.0000 \mathrm{e}+006$ to $-8.0000 \mathrm{e}+005$

$-8.0000 \mathrm{e}+005$ to $-8.00000 \mathrm{e}+005$

$6.0000 \mathrm{e}+005$ to $-4.0000 \mathrm{e}+005$

$4.0000 \mathrm{e}+005$ to $-2.0000 \mathrm{e}+005$

$2.0000 \mathrm{e}+005$ to $0.0000 \mathrm{e}+000$

$0.0000 \mathrm{e}+000$ to $1.3735 \mathrm{e}+005$

interval $=2.0 \mathrm{e}+005$

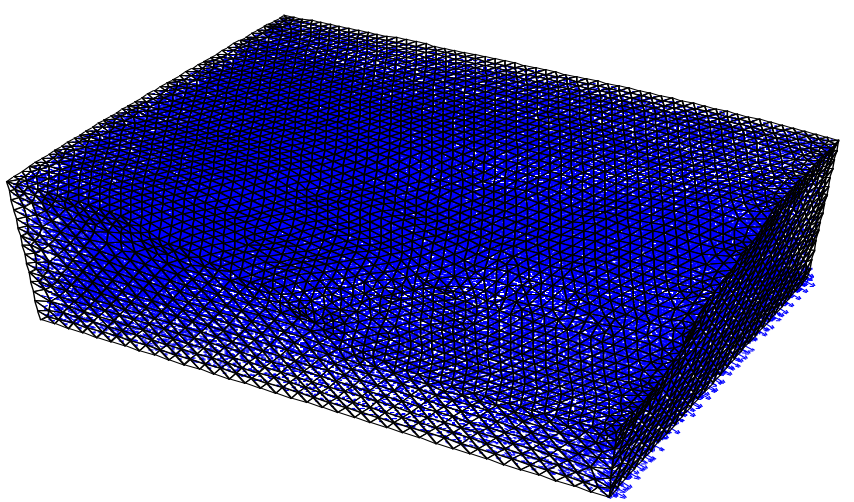

Flow Vectors

Maximum $=2.329 \mathrm{e}-006$ Scale to $\mathrm{Max}=7.000 \mathrm{e}-00$

Fig. 20 Flow vectors of northwest slope under seepage condition 


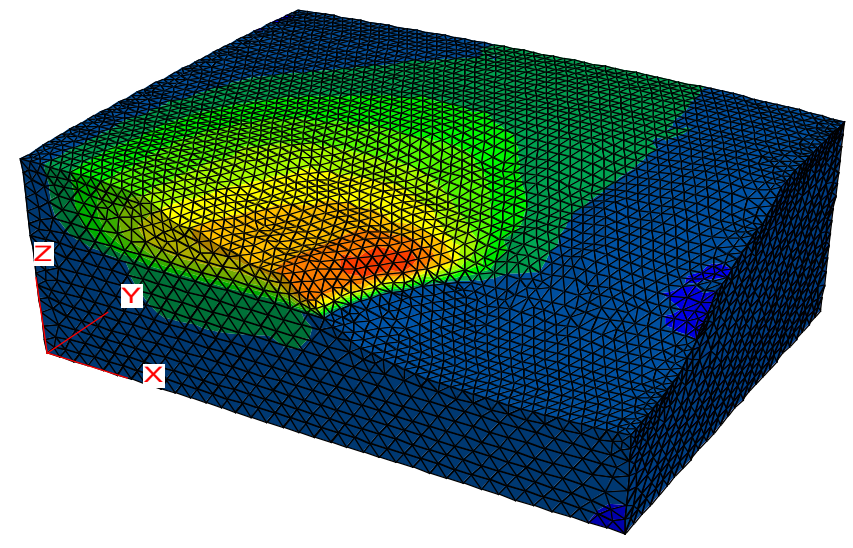

Fig. 21 Contour of X-displacement of northwest slope under seepage condition

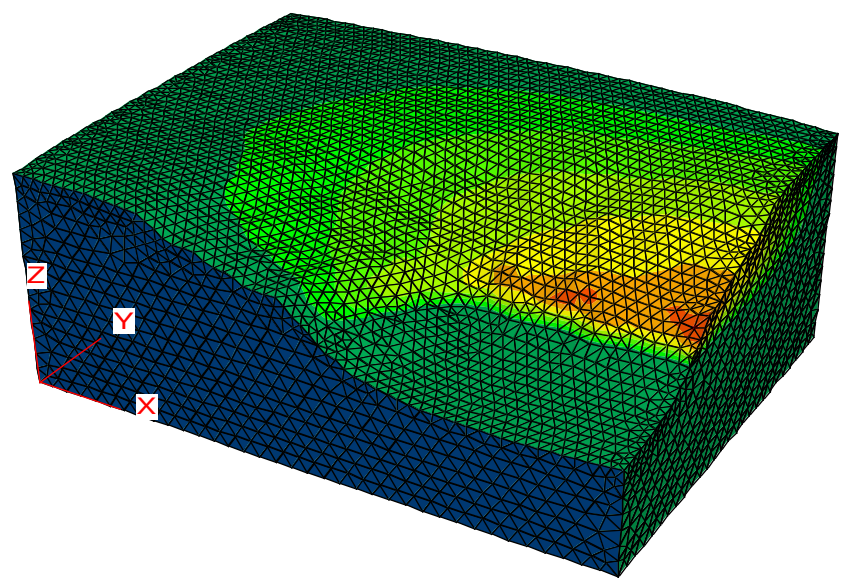

Fig. 22 Contour of Y-displacement of northwest slope under seepage condition

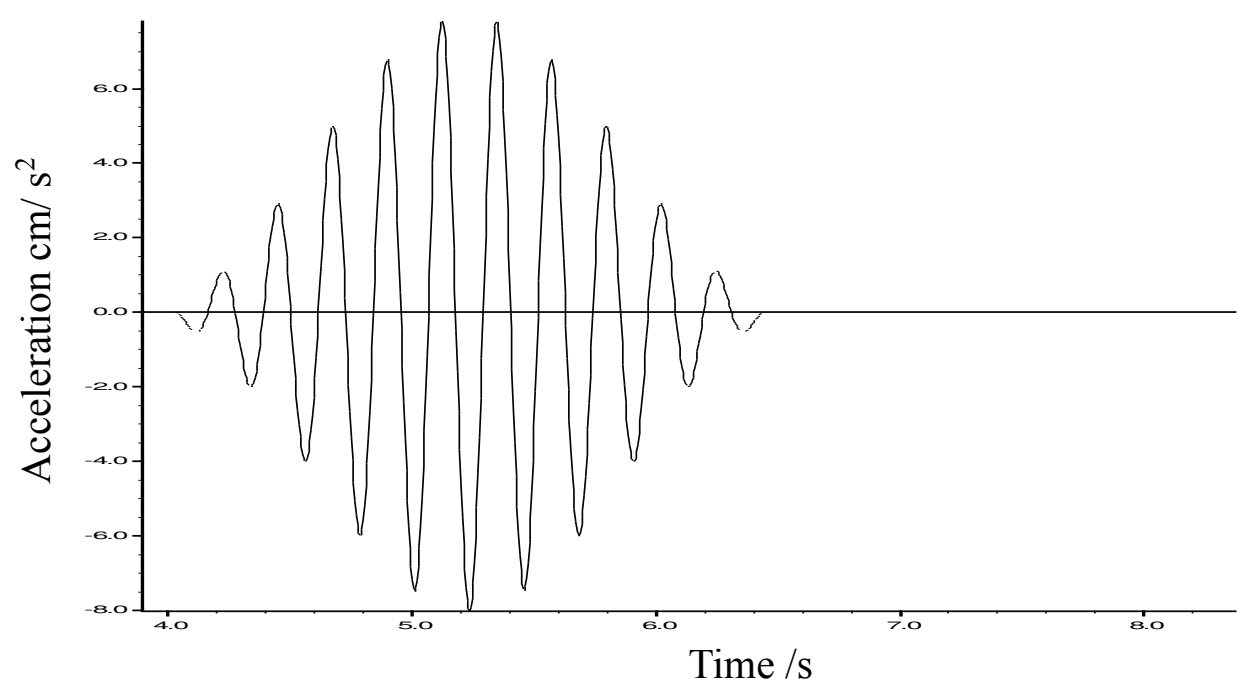

Fig. 23 Horizontal earthquake acceleration curve at model bottom
Contour of X-Displacement Magfac $=0.000 \mathrm{e}+000$

$-1.8309 \mathrm{e}-002$ to $0.0000 \mathrm{e}+000$ $0.0000 \mathrm{e}+000$ to $5.0000 \mathrm{e}-002$ $5.0000 \mathrm{e}-002$ to $1.0000 \mathrm{e}-001$ $1.0000 \mathrm{e}-001$ to $1.5000 \mathrm{e}-00$ $1.5000 \mathrm{e}-001$ to $2.0000 \mathrm{e}-001$ $2.0000 \mathrm{e}-001$ to $2.5000 \mathrm{e}-001$ 2.5000 e-001 to 3.0000 e-00 3.0000 e-001 to $3.5000 \mathrm{e}-00$ .0000 $3.5000 \mathrm{e} 001$ to $4.0000 \mathrm{e}-001$ $4.0000 \mathrm{e}-001$ to $4.4681 \mathrm{e}-001$ Interval $=5.0 \mathrm{e}-002$

Contour of Y-Displacement Magfac $=0.000 \mathrm{e}+000$

$-7.1589 \mathrm{e}-001$ to $-7.0000 \mathrm{e}-001$

$-7.0000 \mathrm{e}-001$ to $-6.0000 \mathrm{e}-001$

$-6.0000 \mathrm{e}-001$ to $-5.0000 \mathrm{e}-001$

$-5.0000 \mathrm{e}-001$ to $-4.0000 \mathrm{e}-001$

$-4.0000 \mathrm{e}-001$ to $-3.0000 \mathrm{e}-001$

$-3.0000 \mathrm{e}-001$ to $-2.0000 \mathrm{e}-001$

$-2.0000 \mathrm{e}-001$ to $-1.0000 \mathrm{e}-001$

$-1.0000 \mathrm{e}-001$ to $0.0000 \mathrm{e}+000$

$0.0000 \mathrm{e}+000$ to $0.0000 \mathrm{e}+000$ Interval $=1.0 \mathrm{e}-001$ 


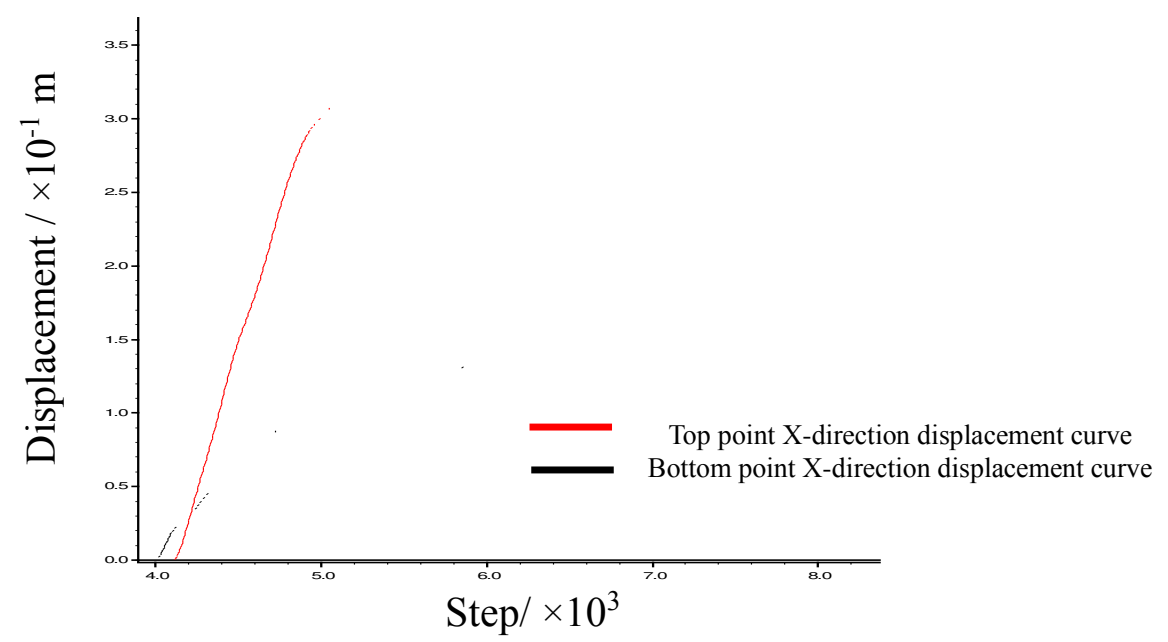

Fig. $24 \mathrm{X}$-displacement curves of bottom and top points of west slope

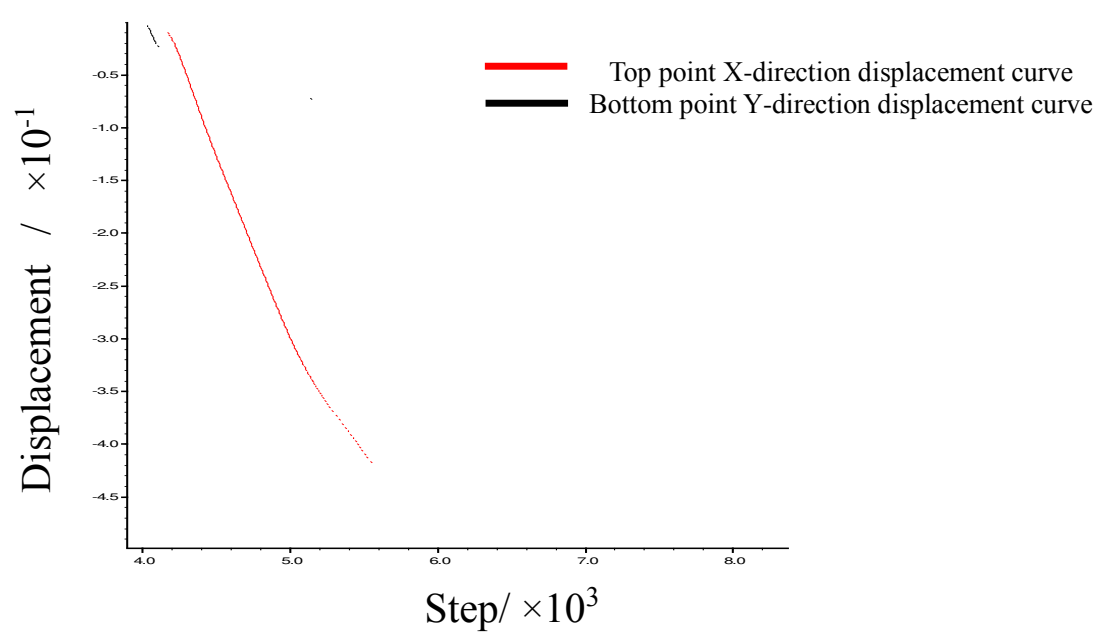

Fig.25 Y-displacement process curves of bottom point and top point in north slope

Table 1 The magnitude of source area and its MPHA of Pingshuo mining

\begin{tabular}{|c|c|c|c|c|}
\hline \multicolumn{2}{|c|}{ Epicenter } & Magnitude & $\begin{array}{c}\text { Displacement from mining } \\
\text { area }(\mathrm{km})\end{array}$ & Mining area (MPHA) \\
\hline \multicolumn{2}{|c|}{$\square$} & 6.5 & 5 & $0.34 \mathrm{~g}$ \\
\hline \multirow{3}{*}{$\square$} & $\square_{\mathrm{A}}$ & 7.0 & 140 & $0.02 \mathrm{~g}$ \\
\cline { 2 - 5 } & $\square_{\mathrm{B}}$ & 8.0 & 45 & $0.17 \mathrm{~g}$ \\
\cline { 2 - 5 } & $\square_{\mathrm{C}}$ & 7.3 & 100 & $0.04 \mathrm{~g}$ \\
\hline \multicolumn{2}{|c|}{$\square$} & 6.7 & 65 & $0.04 \mathrm{~g}$ \\
\hline \multicolumn{2}{|c|}{$\square$} & 7.7 & 210 & $0.02 \mathrm{~g}$ \\
\hline
\end{tabular}

Table 2 Division levels of influence factors

\begin{tabular}{|c|c|c|c|c|c|}
\hline \multirow{2}{*}{ Index factor } & \multirow{2}{*}{ Value } & \multicolumn{4}{|c|}{ Stability level } \\
\cline { 3 - 6 } & I & $\begin{array}{c}\text { II } \\
\text { Stable }\end{array}$ & $\begin{array}{c}\text { III } \\
\text { Basically } \\
\text { unstable }\end{array}$ & $\begin{array}{c}\text { IV } \\
\text { Unstable }\end{array}$ \\
\hline Slope angle & Value & $<15$ & $15-30$ & $30-50$ & $>50$ \\
\hline
\end{tabular}




\begin{tabular}{|c|c|c|c|c|c|}
\hline & Base value & 15 & 22.5 & 35 & 50 \\
\hline \multirow{2}{*}{ Slope height } & Value & $<100$ & $100-200$ & $200-300$ & $>300$ \\
\cline { 2 - 6 } & Base value & 100 & 150 & 250 & 300 \\
\hline \multirow{2}{*}{ Rainfall intensity } & Value & 1 (Weak) & 2 (Weaker) & 3 (Stronger) & 4 (Strong) \\
\cline { 2 - 6 } & Base value & 1 & 2 & 3 & 4 \\
\hline \multirow{2}{*}{$\begin{array}{c}\text { Comprehensive } \\
\text { influence index }\end{array}$} & Value & 1 (Weak) & 2 (Weaker) & 3 (Stronger) & 4 (Strong) \\
\cline { 2 - 6 } $\begin{array}{c}\text { Geological } \\
\text { structure impact }\end{array}$ & Base value & 1 & 2 & 3 & 4 \\
\cline { 2 - 6 } $\begin{array}{c}\text { Well extraction } \\
\text { impact index }\end{array}$ & Base value & 1 (Low) & 2 (Lower) & 3 (Higher) & 4 (High) \\
\cline { 2 - 6 } & Base value & 1 & 2 & 3 & 4 \\
\hline
\end{tabular}


Table 3 Standard value discrete variables

\begin{tabular}{|c|c|c|c|c|}
\hline Assignment & Impact Rating & $\begin{array}{l}\text { Comprehensive } \\
\text { Impact Index of } \\
\text { Landslide } \\
\text { Characteristics }\end{array}$ & $\begin{array}{l}\text { Geological } \\
\text { structure } \\
\text { impact }\end{array}$ & Well extraction impact index \\
\hline 1 & Weak (low) & $\begin{array}{c}\text { Fewer mining } \\
\text { tunnels and } \\
\text { subsidence pits ( }< \\
2 \text { ), Vegetation is very } \\
\text { developed, the rock } \\
\text { is hard, the structure } \\
\text { is complete, and the } \\
\text { weathered rock }\end{array}$ & $\begin{array}{l}\text { Weak tectonic } \\
\text { movement with } \\
\text { only a few } \\
\text { small faults }\end{array}$ & $\begin{array}{l}\text { Gob Span }<40 \mathrm{~m} \text {, area }< \\
800 \mathrm{~m}^{2} \text {,height }<8 \mathrm{~m} \text {,burial depth }< \\
100 \mathrm{~m} \text {, mining area is located below } \\
\text { or away from the top of the slope }\end{array}$ \\
\hline 2 & Weaker (lower) & $\begin{array}{l}\text { Fewer mining } \\
\text { tunnels and } \\
\text { subsidence pits } \\
(2-6) \text {,Vegetation } \\
\text { development, harder } \\
\text { rock, more complete } \\
\text { structure, strongly } \\
\text { weathered rock }\end{array}$ & $\begin{array}{c}\text { Tectonic } \\
\text { movements are } \\
\text { not strong, } \\
\text { only small } \\
\text { faults }\end{array}$ & $\begin{array}{l}\text { Gob Span: } 40 \mathrm{~m}-80 \mathrm{~m} \text {, area: } 800 \\
\mathrm{~m}^{2}-1200 \mathrm{~m}^{2}, \text { height: } 8 \mathrm{~m}-20 \mathrm{~m} \text {,burial } \\
\text { depth: } 100 \mathrm{~m}-200 \mathrm{~m} \text {,mining area is } \\
\text { located below the top of the slope }\end{array}$ \\
\hline 3 & Strong (higher) & $\begin{array}{l}\text { Mining tunnels and } \\
\text { subsidence pits are } \\
\text { more } \\
\text { (6-10), Vegetation } \\
\text { is relatively } \\
\text { developed, rocks are } \\
\text { broken, rock and soil } \\
\text { are incomplete, and } \\
\text { fully weathered rocks }\end{array}$ & $\begin{array}{l}\text { Strong tectonic } \\
\text { movement, } \\
\text { large fault } \\
\text { zone, dense } \\
\text { faults }\end{array}$ & $\begin{array}{c}\text { Gob Span: } 80 \mathrm{~m}-120 \mathrm{~m} \text {,area: } 1200 \\
\mathrm{~m}^{2}-2700 \mathrm{~m}^{2}, \text { height: } 20 \mathrm{~m}-30 \mathrm{~m} \text {,burial } \\
\text { depth: } 200 \mathrm{~m}-300 \mathrm{~m}, \text { mining area is } \\
\text { located below the slope waist }\end{array}$ \\
\hline 4 & Strong (high) & $\begin{array}{c}\text { There are many } \\
\text { mining tunnels and } \\
\text { subsidence pits ( }> \\
\text { 10), Vegetation is not } \\
\text { developed, rocks are } \\
\text { particularly broken, } \\
\text { weak structural } \\
\text { surfaces are } \\
\text { developed, and rock } \\
\text { and soil are } \\
\text { particularly } \\
\text { incomplete }\end{array}$ & $\begin{array}{l}\text { Strong tectonic } \\
\text { movement, } \\
\text { huge fault } \\
\text { zone, dense } \\
\text { faults }\end{array}$ & $\begin{array}{c}\text { Gob Span }>120 \mathrm{~m} \text {,area }> \\
2700 \mathrm{~m}^{2} \text {, height }>30 \mathrm{~m} \text {,burial depth }> \\
300 \mathrm{~m} \text {, mining area is located at the } \\
\text { foot of the slope }\end{array}$ \\
\hline
\end{tabular}

Table 4 Weight computing results

\begin{tabular}{|c|c|c|c|c|c|c|}
\hline project & $\begin{array}{c}\text { Slope } \\
\text { angle }\end{array}$ & $\begin{array}{c}\text { Slope } \\
\text { height }\end{array}$ & $\begin{array}{c}\text { Rainfall } \\
\text { intensity }\end{array}$ & $\begin{array}{c}\text { Comprehensive } \\
\text { influence index }\end{array}$ & $\begin{array}{c}\text { Geological } \\
\text { structure impact }\end{array}$ & $\begin{array}{c}\text { Well extraction } \\
\text { impact index }\end{array}$ \\
\hline$C_{i}$ & 45 & 120 & 1.5 & 2 & 1.5 & 0.2 \\
\hline$S_{i}$ & 30.63 & 200 & 2.5 & 2.5 & 2.5 & 0.5 \\
\hline$W_{i}$ & 0.67 & 0.6 & 0.6 & 0.8 & 0.6 & 0.4 \\
\hline$W_{i}$ & 0.18 & 0.16 & 0.16 & 0.22 & 0.16 & 0.12 \\
\hline
\end{tabular}

Table 5 Stability coefficient of section 1

\begin{tabular}{|c|c|c|c|}
\hline \multirow{2}{*}{$\begin{array}{c}\text { Earthquake } \\
\text { intensity }\end{array}$} & \multicolumn{3}{|c|}{ Natural drainage rate of slope } \\
\cline { 2 - 4 } & $0 \%$ & $50 \%$ & $100 \%$ \\
\hline 0 & 1.0742 & 1.2481 & 1.4275 \\
\hline VII & 0.9165 & 1.0623 & 1.2212 \\
\hline VIII & 0.7949 & 0.9186 & 1.0606 \\
\hline
\end{tabular}


Table 6 Stability coefficient of section 2

\begin{tabular}{|c|c|c|c|}
\hline \multirow{2}{*}{$\begin{array}{c}\text { Earthquake } \\
\text { intensity }\end{array}$} & \multicolumn{3}{|c|}{ Natural drainage rate of slope } \\
\cline { 2 - 4 } & $0 \%$ & $50 \%$ & $100 \%$ \\
\hline 0 & 1.0002 & 1.1939 & 1.4305 \\
\hline VII & 0.8583 & 1.0175 & 1.2278 \\
\hline VIII & 0.7474 & 0.8795 & 1.0675 \\
\hline
\end{tabular}

Table 7 The physical mechanical parameters of rock mass of Antaibao open pit mine in Shanxi province

\begin{tabular}{|c|c|c|c|c|c|c|c|}
\hline & Lithology & $\begin{array}{c}\text { Bulk density } \\
\left(\mathrm{kg} / \mathrm{m}^{3}\right)\end{array}$ & $\begin{array}{c}\text { Elastic } \\
\text { Modulus } \\
(\mathrm{Pa})\end{array}$ & $\begin{array}{c}\text { Poisson's } \\
\text { ratio }\end{array}$ & $\begin{array}{c}\text { Tensile } \\
\text { strength } \\
(\mathrm{Pa})\end{array}$ & $\begin{array}{c}\text { Adhesion } \\
(\mathrm{Pa})\end{array}$ & $\begin{array}{c}\text { Internal } \\
\text { friction } \\
\text { angle }(\mathrm{deg})\end{array}$ \\
\hline 1 & Loess & 1960 & $1.5 \mathrm{e} 8$ & 0.42 & $1.0 \mathrm{e} 3$ & $5.0 \mathrm{e} 4$ & 20 \\
\hline 2 & $\begin{array}{c}\text { Weathered } \\
\text { sandstone }\end{array}$ & 2300 & $2.0 \mathrm{e} 9$ & 0.36 & $5.0 \mathrm{e} 4$ & $1.0 \mathrm{e} 6$ & 33 \\
\hline 3 & Sandstone & 2380 & $4.2 \mathrm{e} 9$ & 0.32 & $1.0 \mathrm{e} 5$ & $1.2 \mathrm{e} 6$ & 35 \\
\hline
\end{tabular}

Table 8 Physical and mechanical parameters of fluid in rock mass

\begin{tabular}{|c|c|c|c|c|c|}
\hline & Density $\left(\mathrm{kg} / \mathrm{m}^{3}\right)$ & $\begin{array}{c}\text { Bulk modulus } \\
(\mathrm{MP})\end{array}$ & $\begin{array}{c}\text { Undrained } \\
\text { coefficient }\end{array}$ & $\begin{array}{c}\text { Residual } \\
\text { saturation }\end{array}$ & $\begin{array}{c}\text { Viscosity } \\
\text { ratio }\end{array}$ \\
\hline Water & 1000 & 1.0 & 0 & 0 & 1 \\
\hline Air & 0 & 0 & 0 & 0 & 1 \\
\hline
\end{tabular}




\section{Figures}

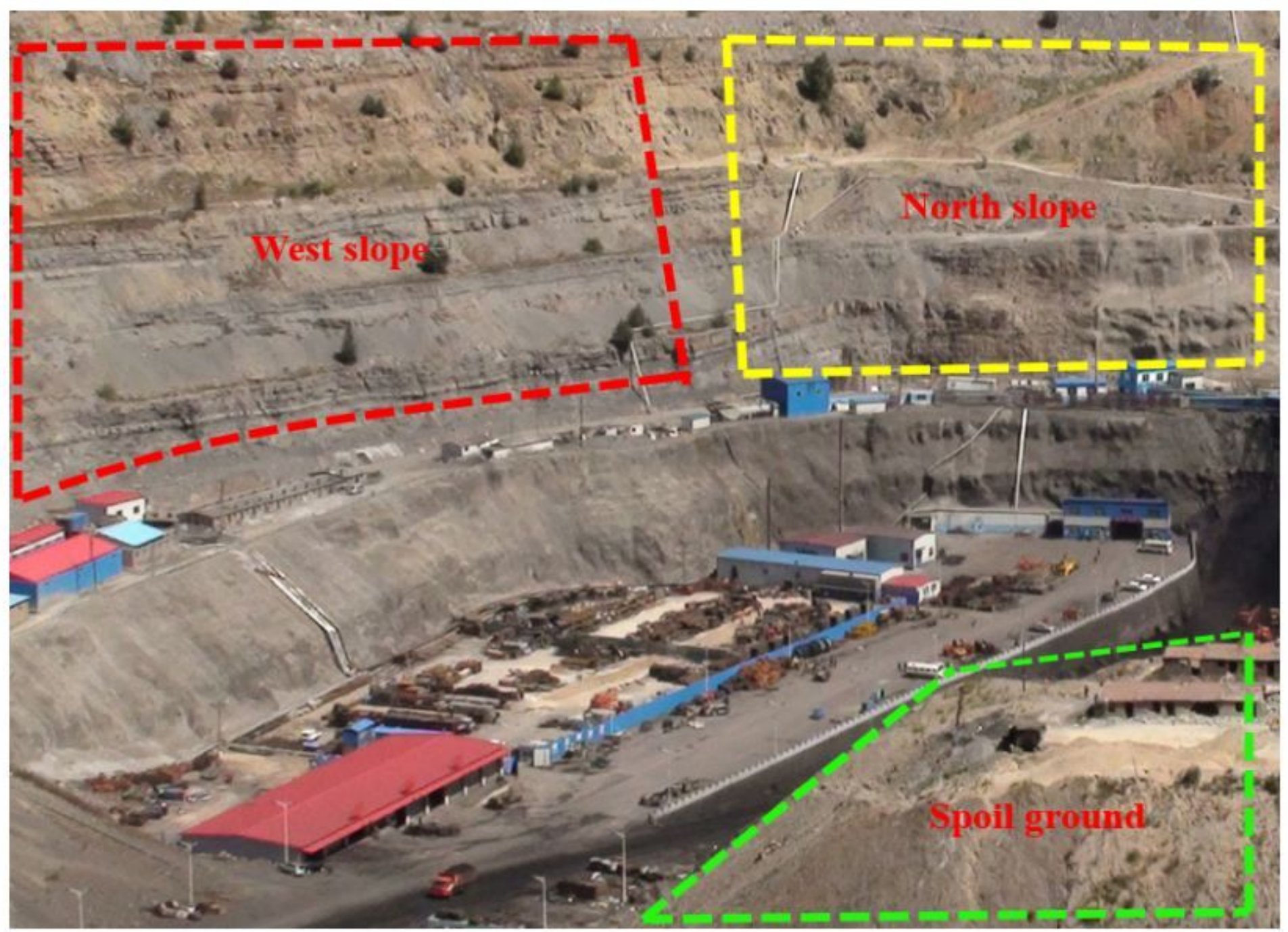

Figure 1

Mining area panorama 


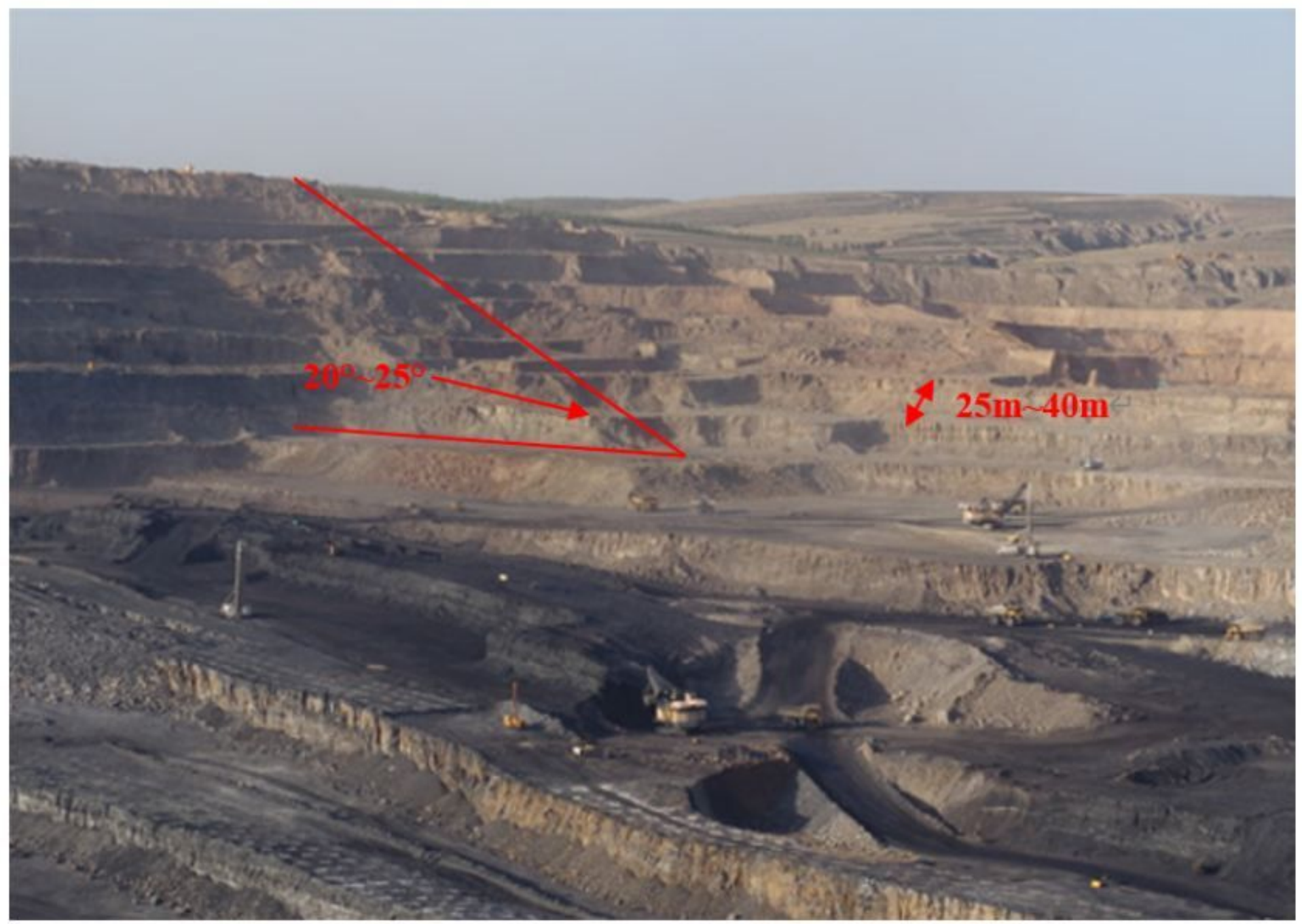

Figure 2

The topography of mining area

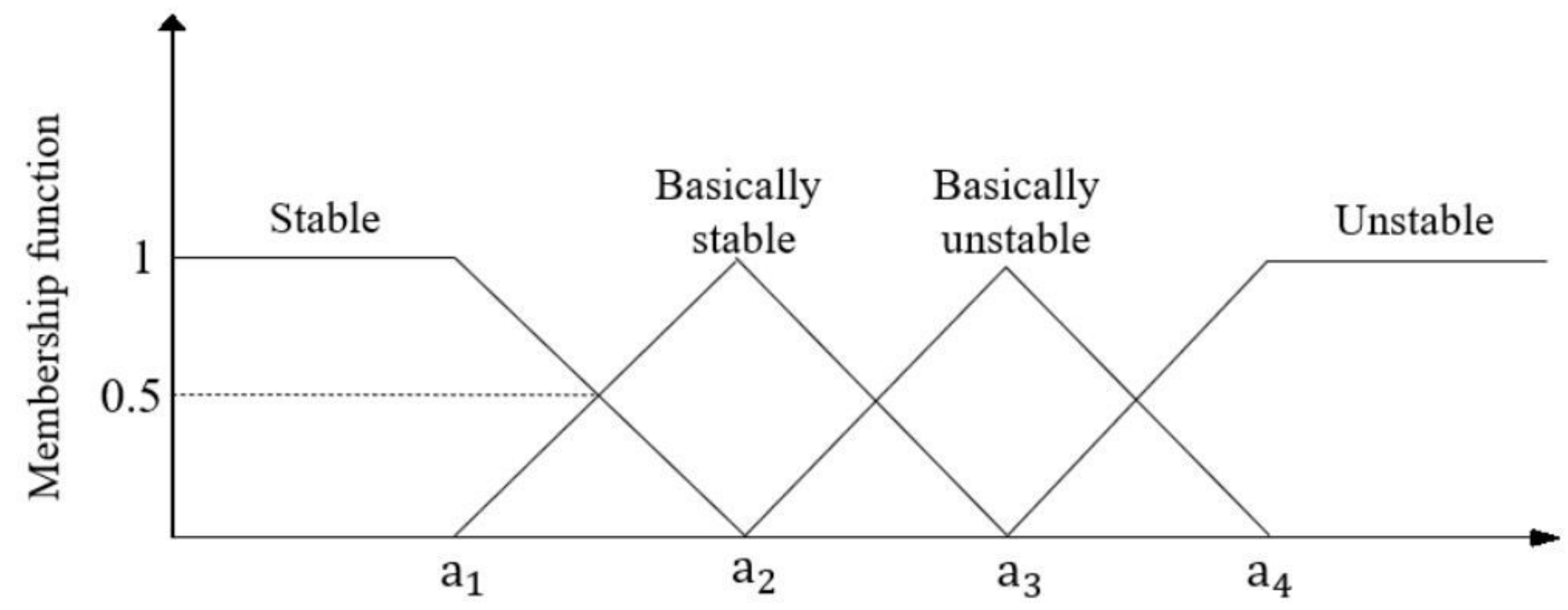


Figure 3

Membership distribution function

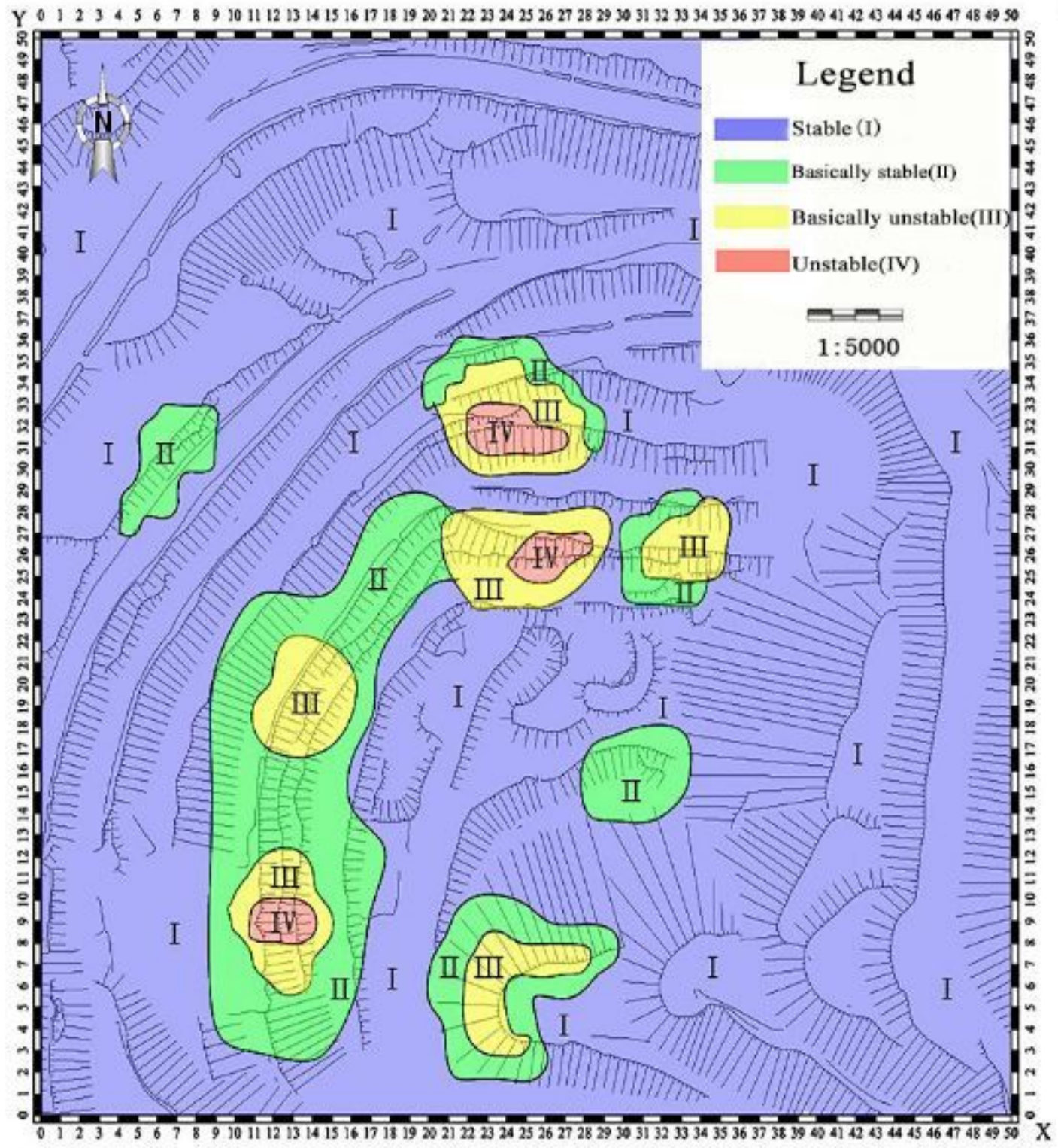

Figure 4

Results cloud picture of the slope stability fuzzy comprehensive evaluation for Antaibao open pit mine 


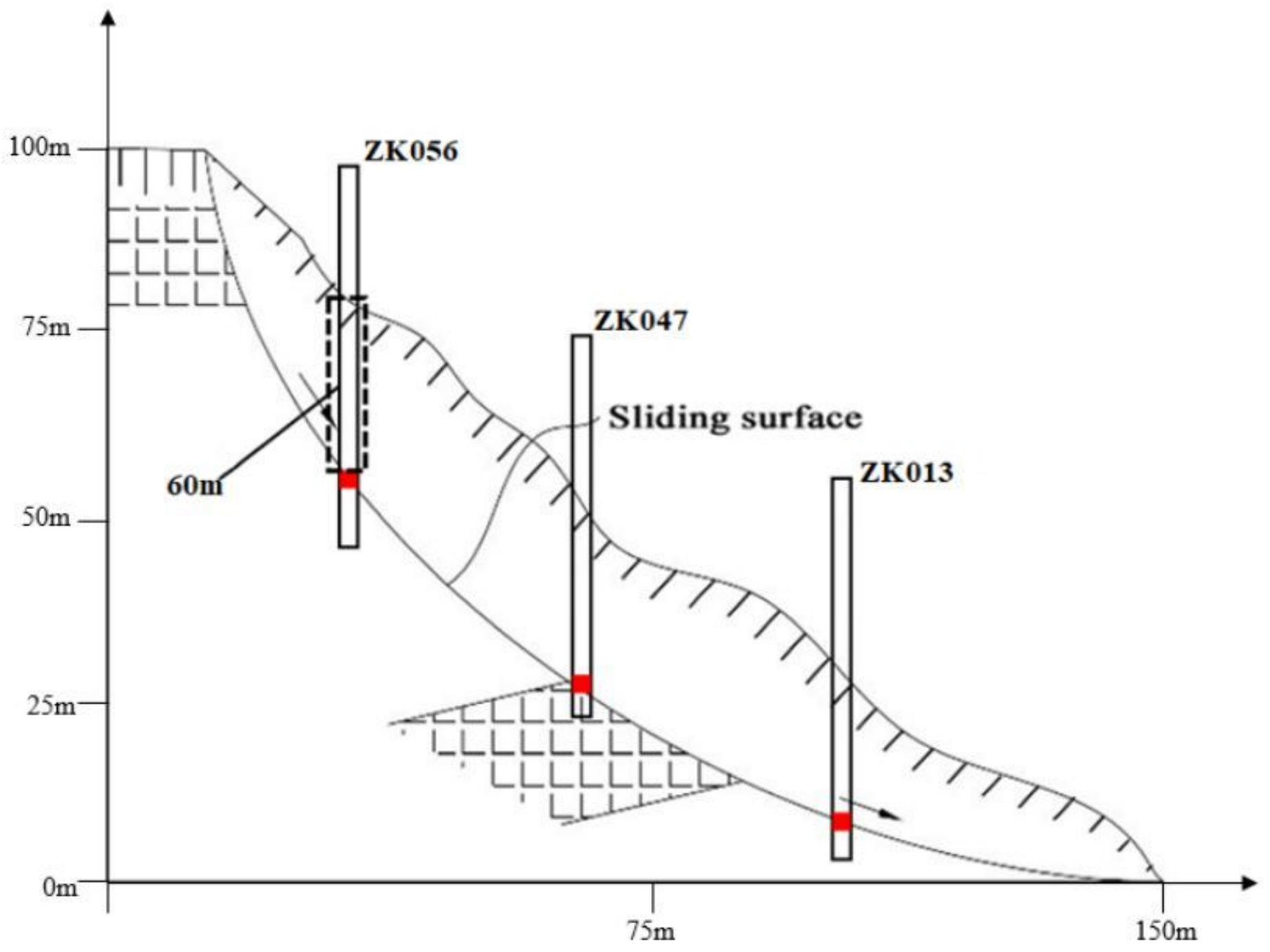

Figure 5

Schematic diagram of sliding surface determination 


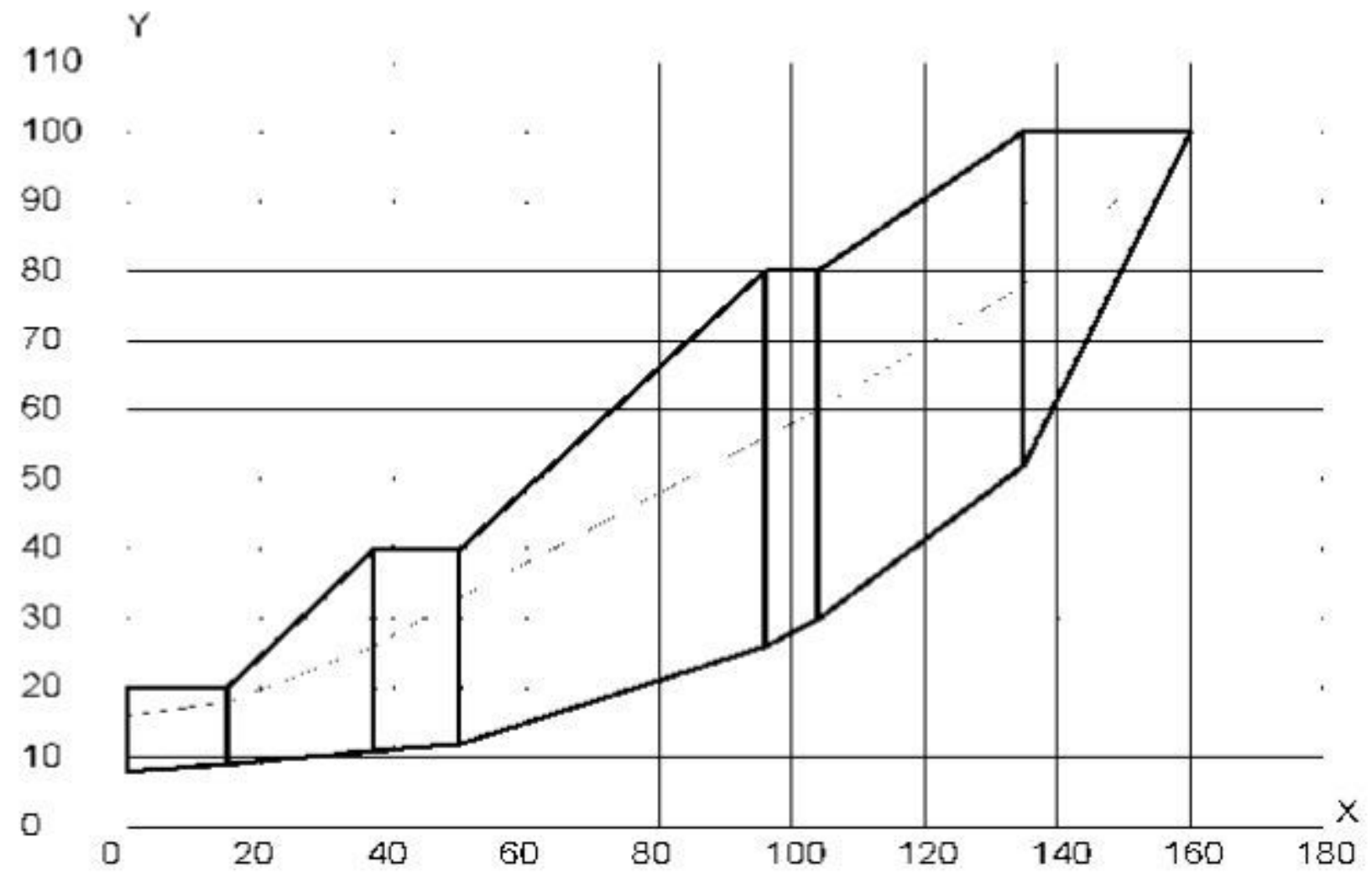

Figure 6

MSARMA method computation model of section 1

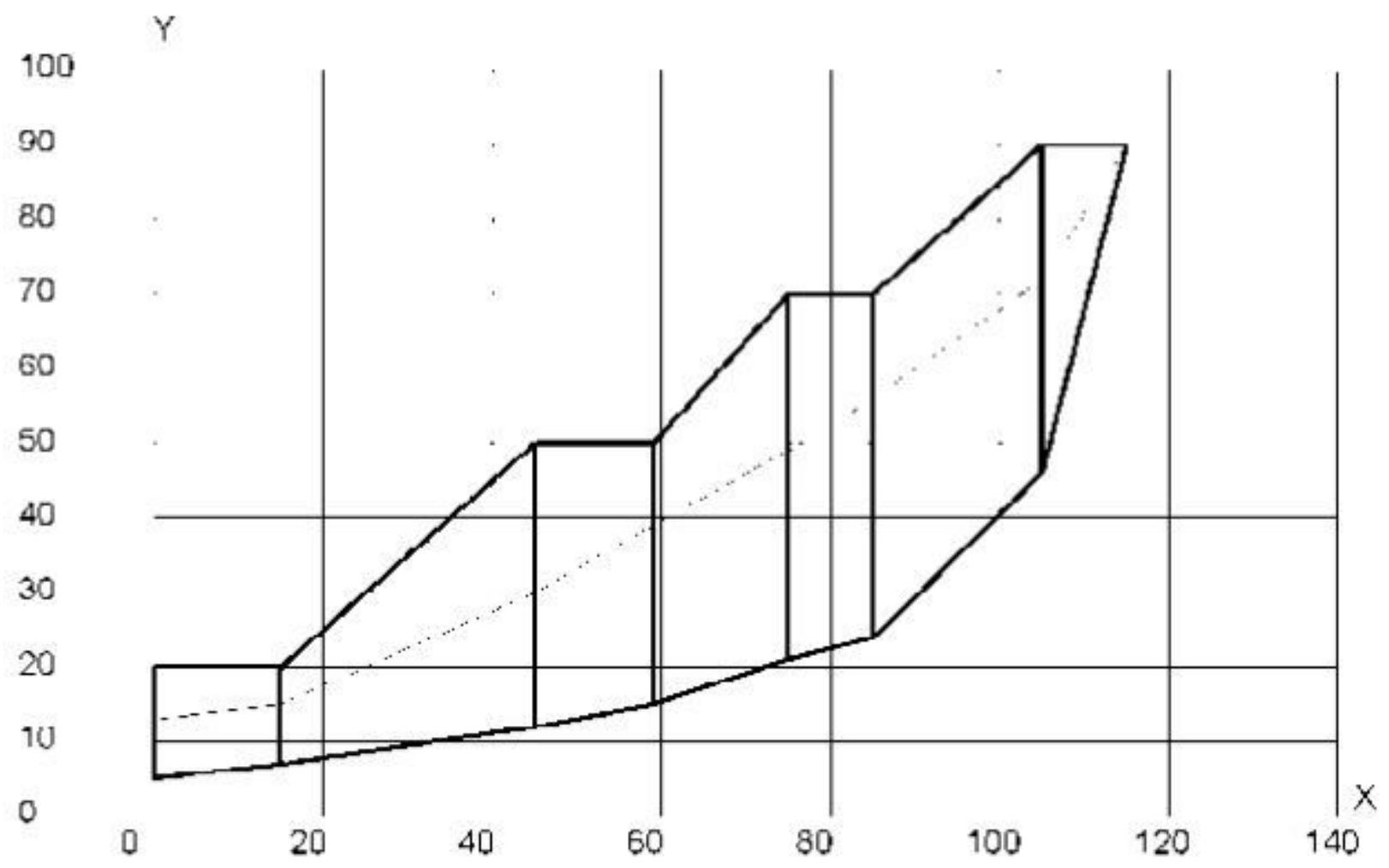

Figure 7 
MSARMA method computation model of section 2

Fs

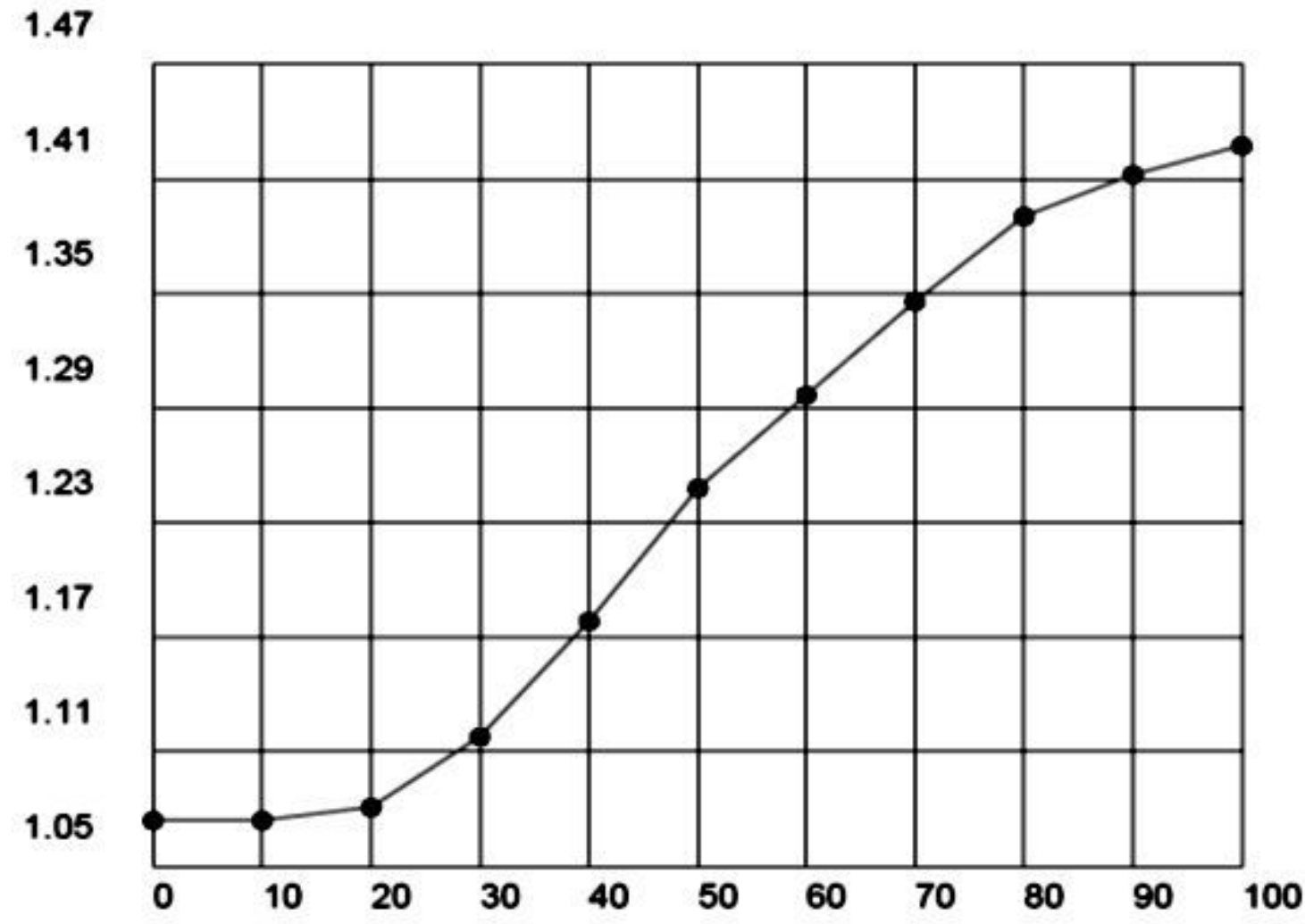

Figure 8

Influence curve of driange rate on slope stability in section 1 
Fs

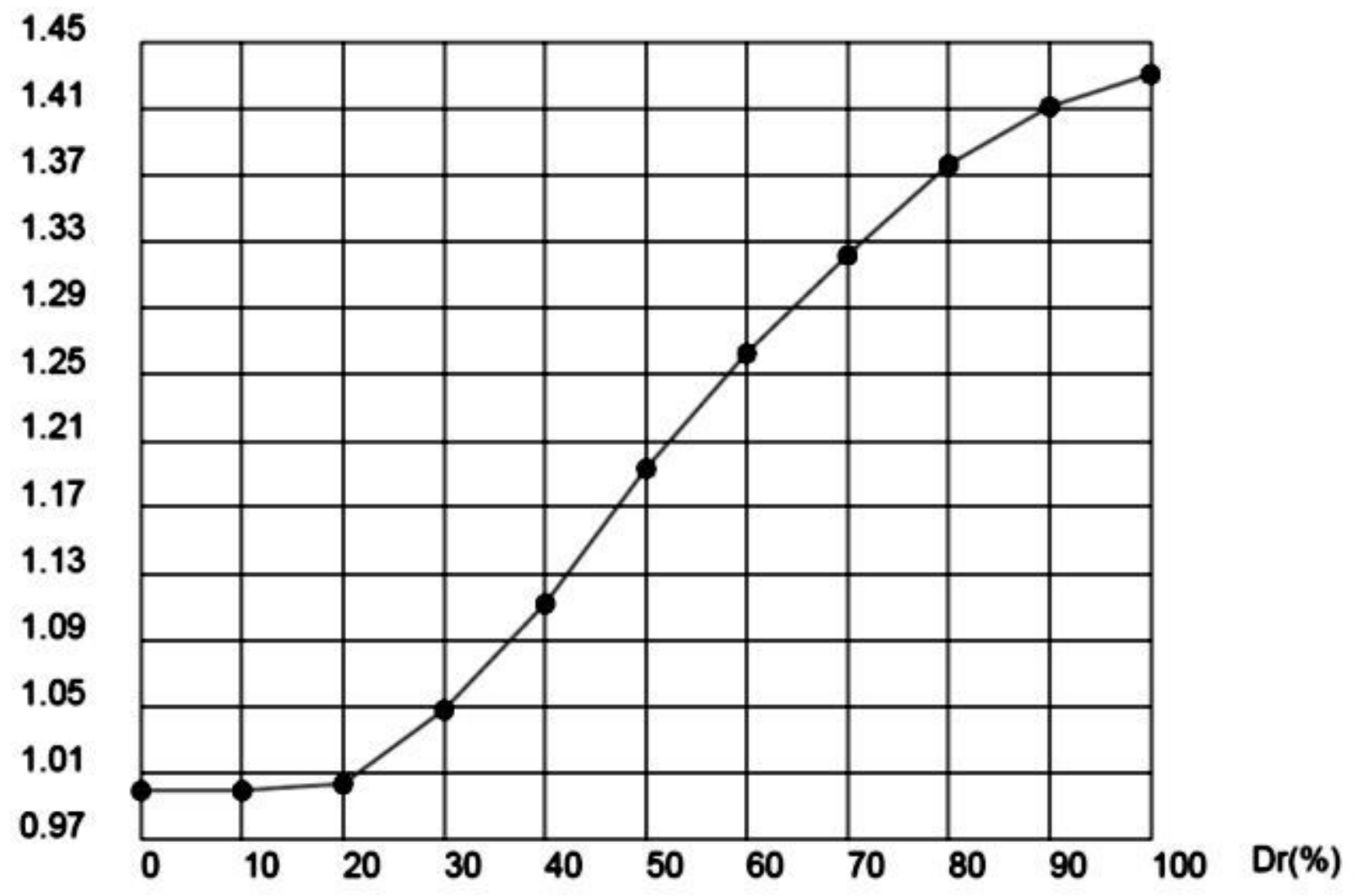

Figure 9

Influence curve of driange rate on slope stability in section 2 


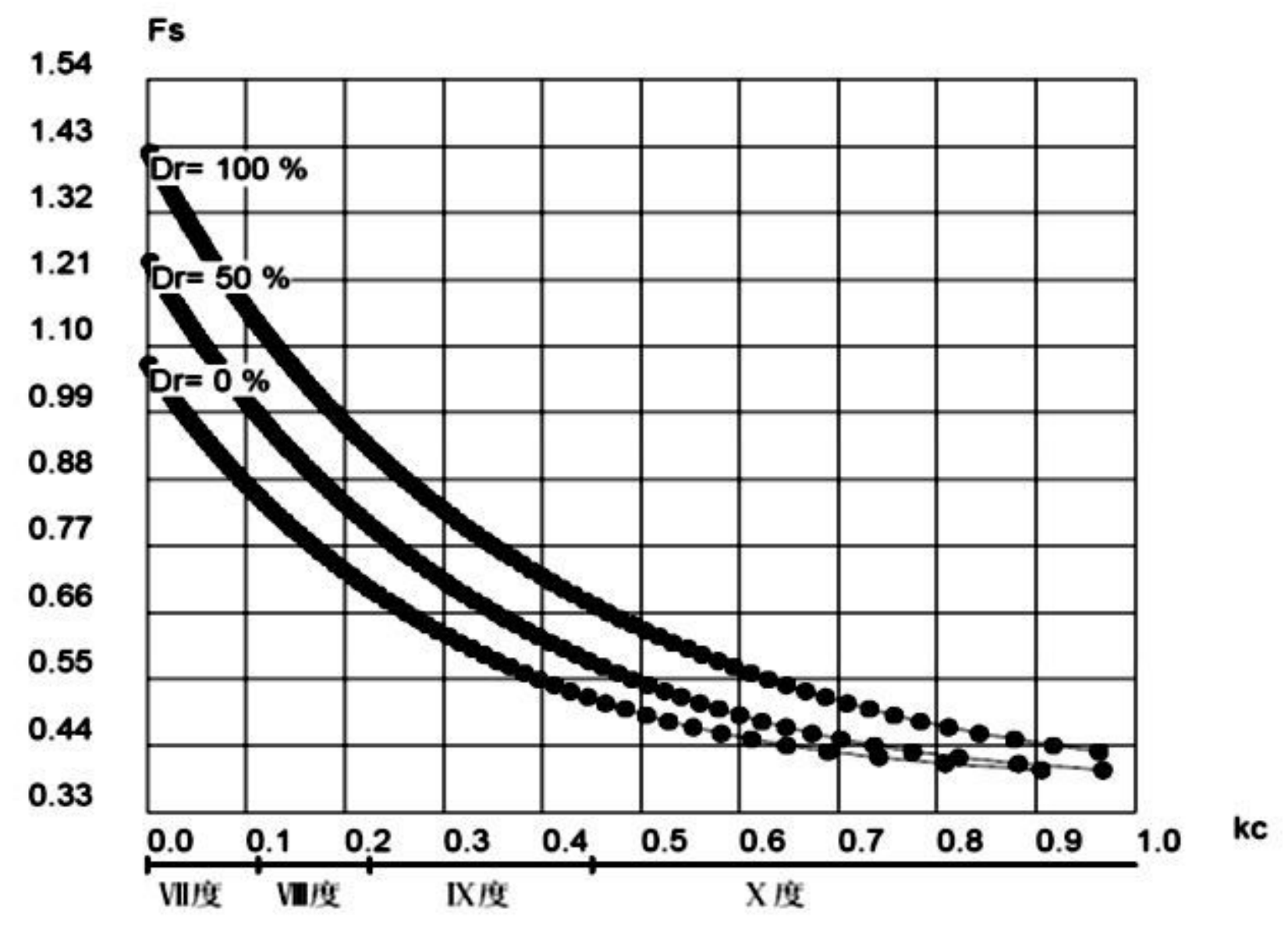

Figure 10

Influence curve of seismic coefficient on slope stability in section 1 


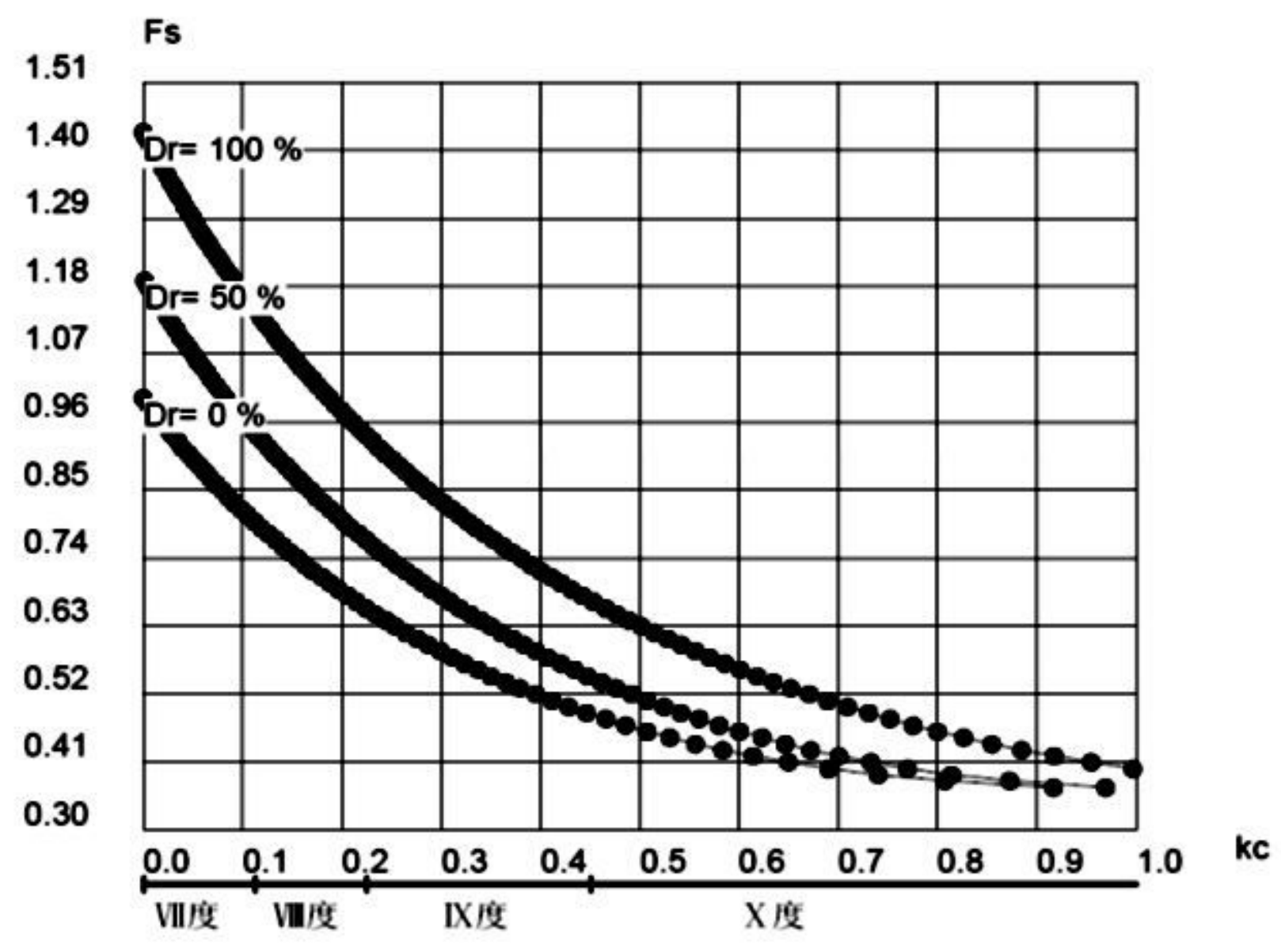

Figure 11

Influence curve of seismic coefficient on slope stability in section 2

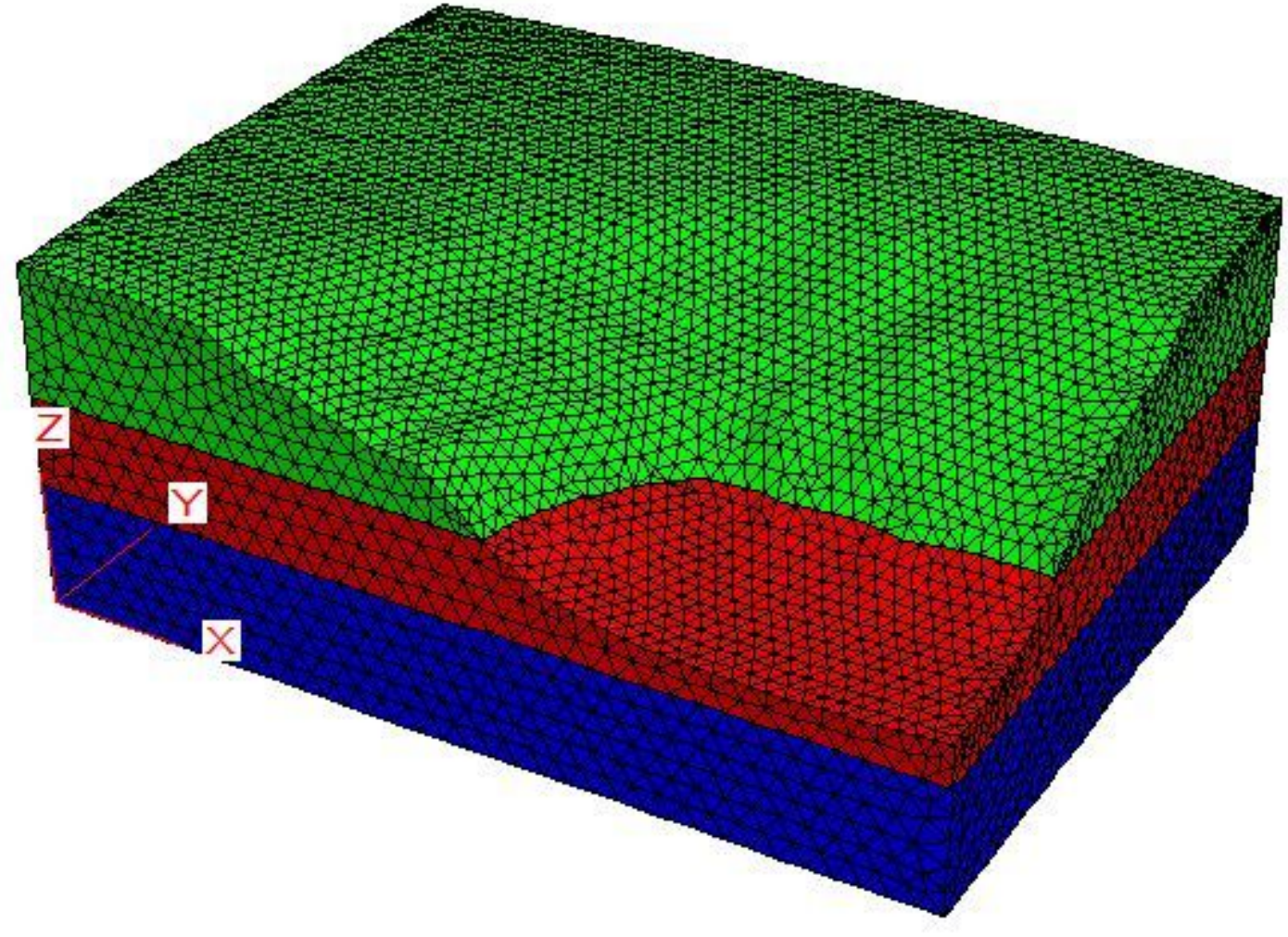

Block Group sandstone weatheredsandstone loess 
Figure 12

Engineering geological model of northwest slope

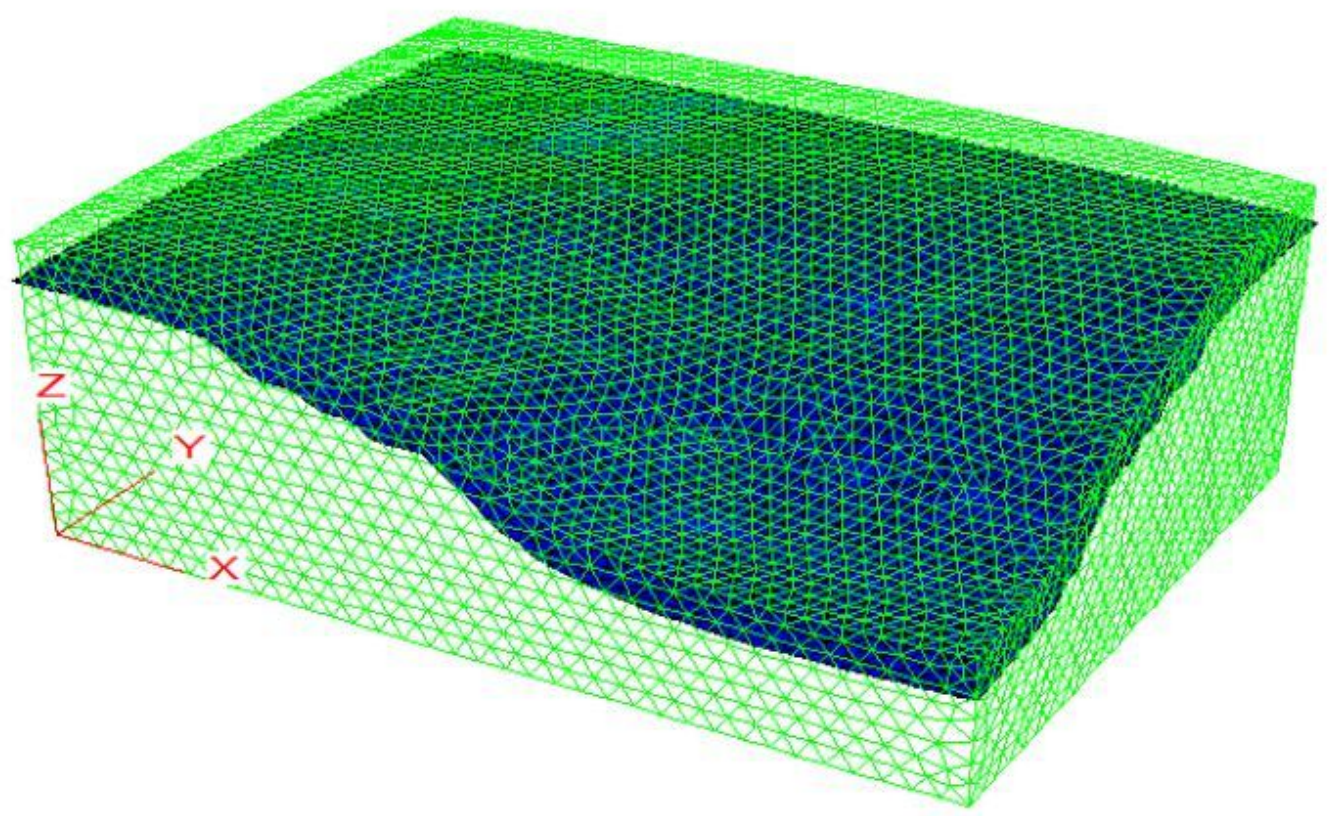

Water Surfaces

Sketch

Magfac $=0.000 \mathrm{e}^{+000}$

\section{Figure 13}

Water surface position in model

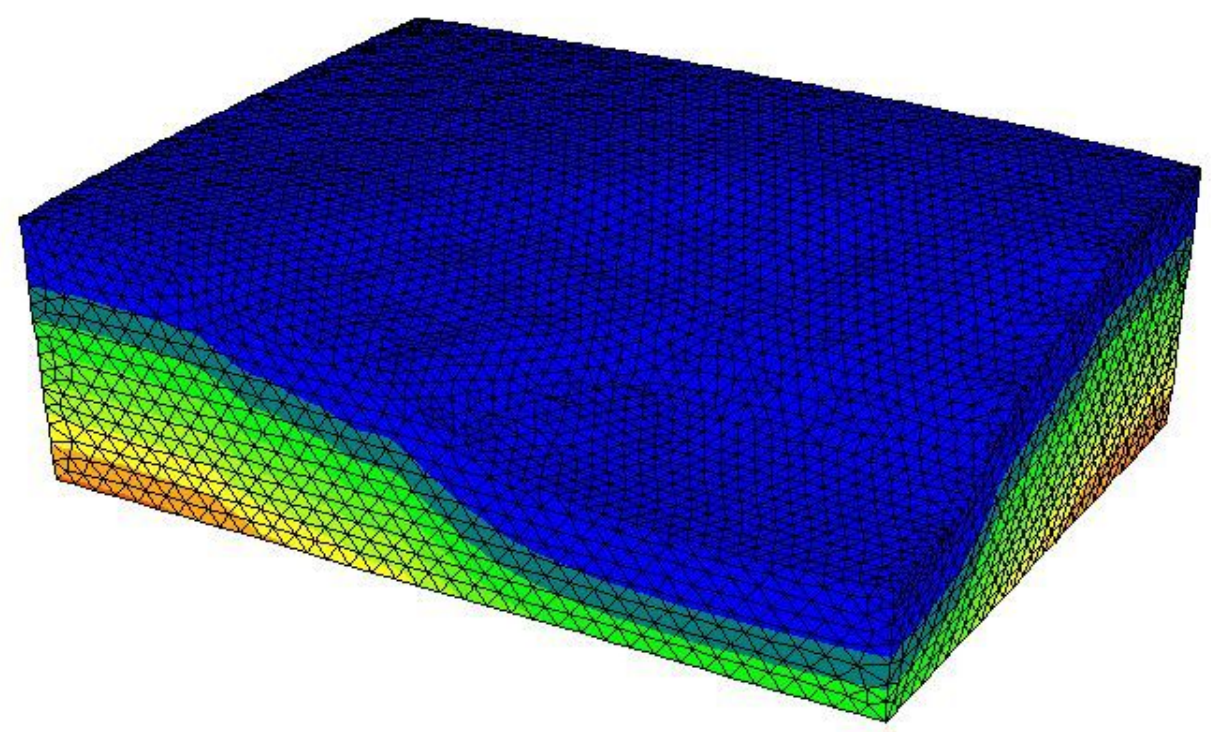

Contour of Pore Pressure

Magfac $=0.000 \mathrm{e}+000$

$0.0000 \mathrm{e}+000$ to $5.0000 \mathrm{e}+005$

$5.0000 \mathrm{e}+005$ to $1.0000 \mathrm{e}+006$

$1.0000 \mathrm{e}+006$ to $1.5000 \mathrm{e}+006$ $1.5000 \mathrm{e}+006$ to $2.0000 \mathrm{e}+006$ $2.0000 \mathrm{e}+006$ to $2.5000 \mathrm{e}+006$ $2.5000 \mathrm{e}+006$ to $3.0000 \mathrm{e}+006$ $3.0000 \mathrm{e}+006$ to $3.5000 \mathrm{e}+006$ $3.5000 \mathrm{e}+006$ to $3.5681 \mathrm{e}+006$ Interval $=5.0 \mathrm{e}+005$

Figure 14

Contour of pore pressure 


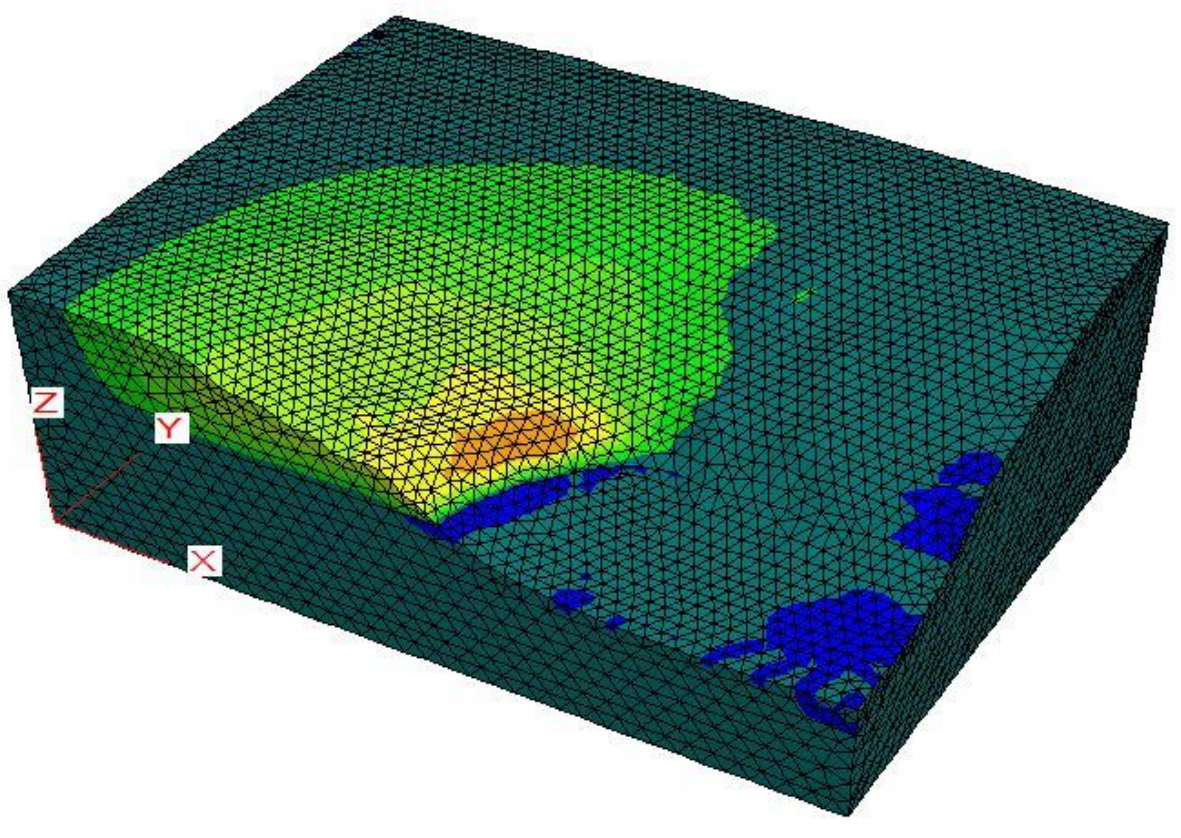

Figure 15

Contour of X-displacement of northwest slope under natural condition

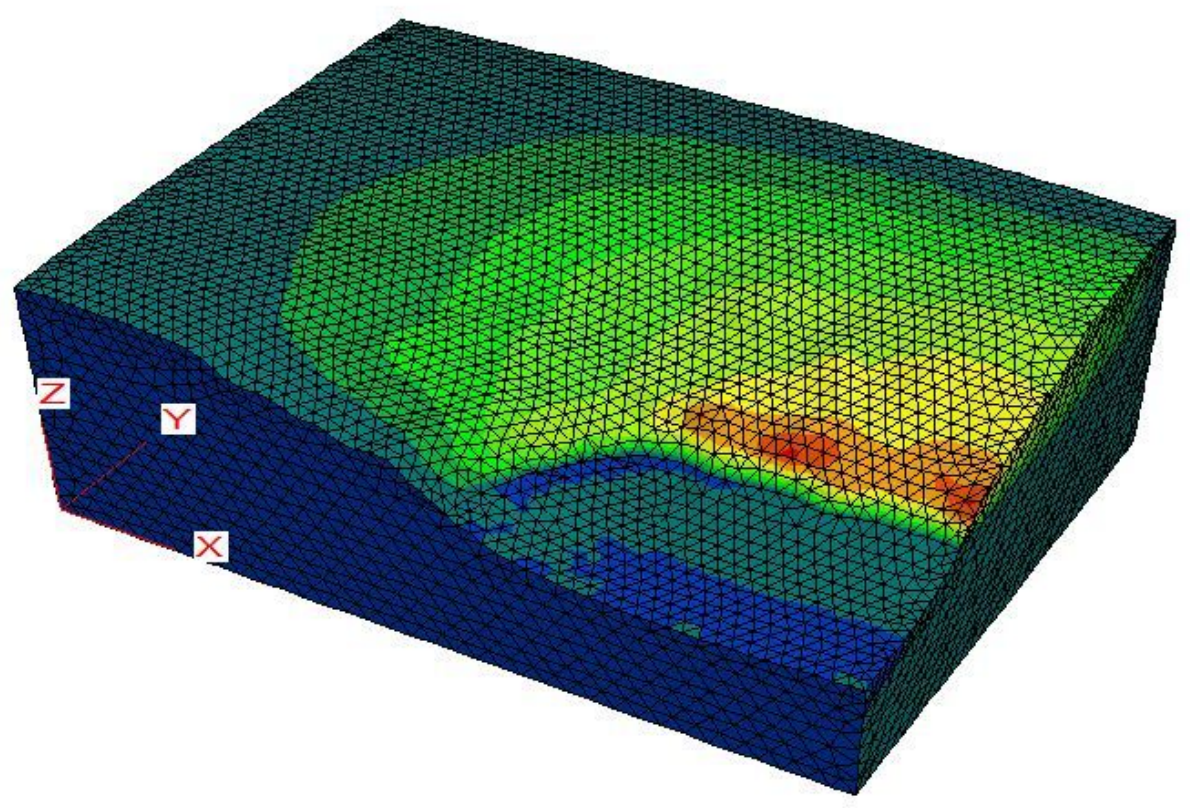

Figure 16

Contour of Y-displacement of northwest slope under natural condition
Contour of X-Displacement Magfac $=0.000 \mathrm{e}+000$

$-1.6341 \mathrm{e}-002$ to $0.0000 \mathrm{e}+000$ $0.0000 \mathrm{e}+000$ to $5.0000 \mathrm{e}-002$ $5.0000 \mathrm{e}-002$ to $1.0000 \mathrm{e}-001$ $1.0000 \mathrm{e}-001$ to $1.5000 \mathrm{e}-001$ $1.5000 \mathrm{e}-001$ to $2.0000 \mathrm{e}-001$ $2.0000 \mathrm{e}-001$ to $2.5000 \mathrm{e}-001$ $2.5000 \mathrm{e}-001$ to $3.0000 \mathrm{e}-001$ $3.0000 \mathrm{e}-001$ to $3.0575 \mathrm{e}-001$ Interval $=5.0 \mathrm{e}-002$

Contour of Y-Displacement Magfac $=0.000 \mathrm{e}+000$

$-4.1718 \mathrm{e}-001$ to $-4.0000 \mathrm{e}-001$ $-4.0000 \mathrm{e}-001$ to $-3.5000 \mathrm{e}-001$ $-3.5000 \mathrm{e}-001$ to $-3.0000 \mathrm{e}-001$ $-3.0000 \mathrm{e}-001$ to $-2.5000 \mathrm{e}-001$ $-2.5000 \mathrm{e}-001$ to $-2.0000 \mathrm{e}-001$ $-2.0000 \mathrm{e}-001$ to $-1.5000 \mathrm{e}-001$ $-1.5000 \mathrm{e}-001$ to $-1.0000 \mathrm{e}-001$ $-1.0000 \mathrm{e}-001$ to $-5.0000 \mathrm{e}-002$ $-5.0000 \mathrm{e}-002$ to $0.0000 \mathrm{e}+000$ $0.0000 \mathrm{e}+000$ to $2.4887 \mathrm{e}-003$ Interval $=5.0 \mathrm{e}-002$ 


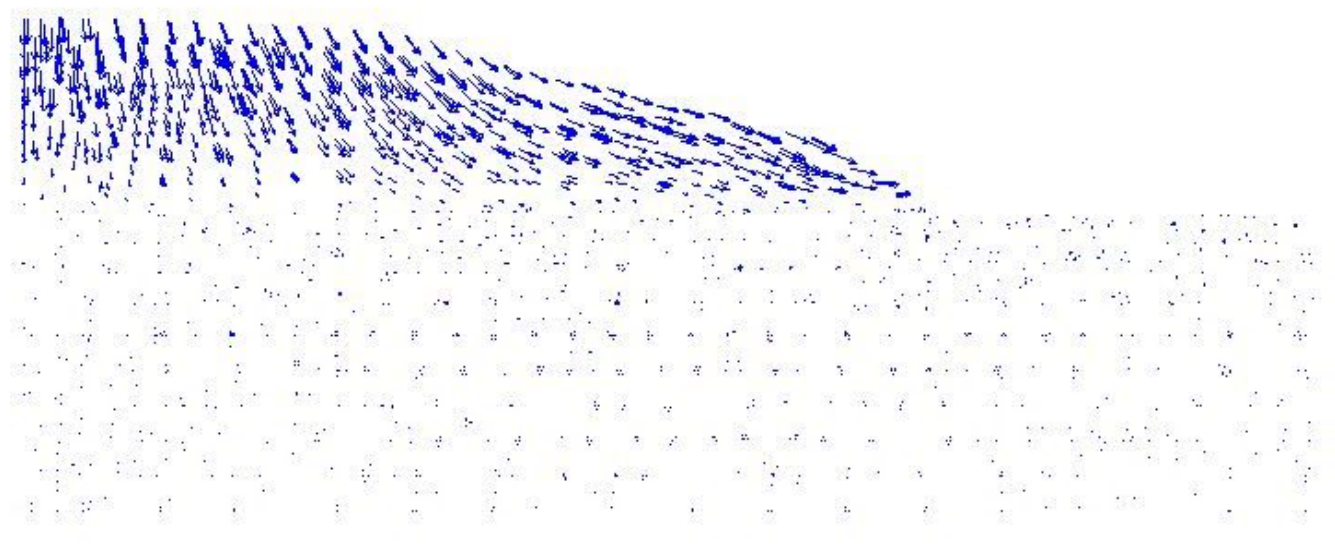

Displacement

Plane: on

Maximum $=3.422 \mathrm{e}-001$

Scale to Max $=3.000 \mathrm{e}+000$

\section{Figure 17}

Displacement vectors of $Y=200 m$ section

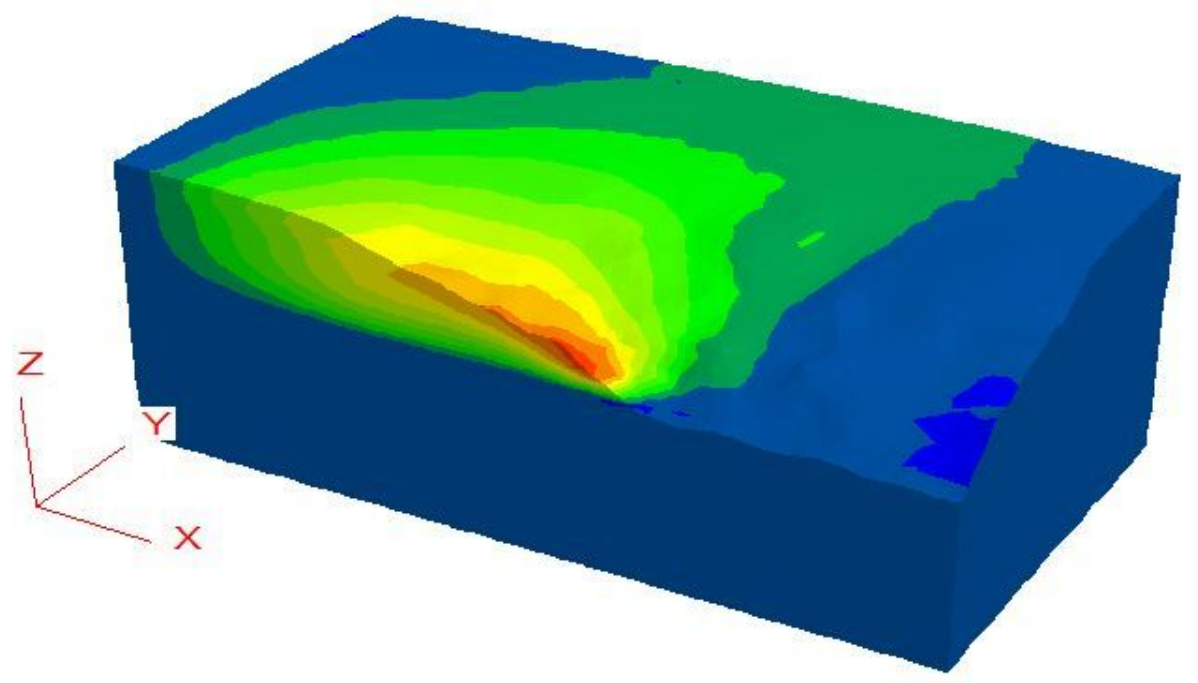

Contour of X-Displacement Plane: on behind Magfac $=0.000 \mathrm{e}^{+} 000$

$-1.6341 \mathrm{e}-002$ to $0.0000 \mathrm{e}+000$ $0.0000 \mathrm{e}+000$ to $2.5000 \mathrm{e}-002$ $2.5000 \mathrm{e}-002$ to $5.0000 \mathrm{e}-002$ $5.0000 \mathrm{e}-002$ to $7.5000 \mathrm{e}-002$ $7.5000 \mathrm{e}-002$ to $1.0000 \mathrm{e}-001$ $1.0000 \mathrm{e}-001$ to $1.2500 \mathrm{e}-001$ $1.2500 \mathrm{e}-001$ to $1.5000 \mathrm{e}-001$ $1.5000 \mathrm{e}-001$ to $1.7500 \mathrm{e}-001$ $1.7500 \mathrm{e}-001$ to $2.0000 \mathrm{e}-001$ $2.0000 \mathrm{e}-001$ to $2.2500 \mathrm{e}-001$ $2.2500 \mathrm{e}-001$ to $2.4774 \mathrm{e}-001$ Interval $=2.5 \mathrm{e}-002$

Figure 18

Contour of $X$-displacement of $Y=200 \mathrm{~m}$ section and rear part 

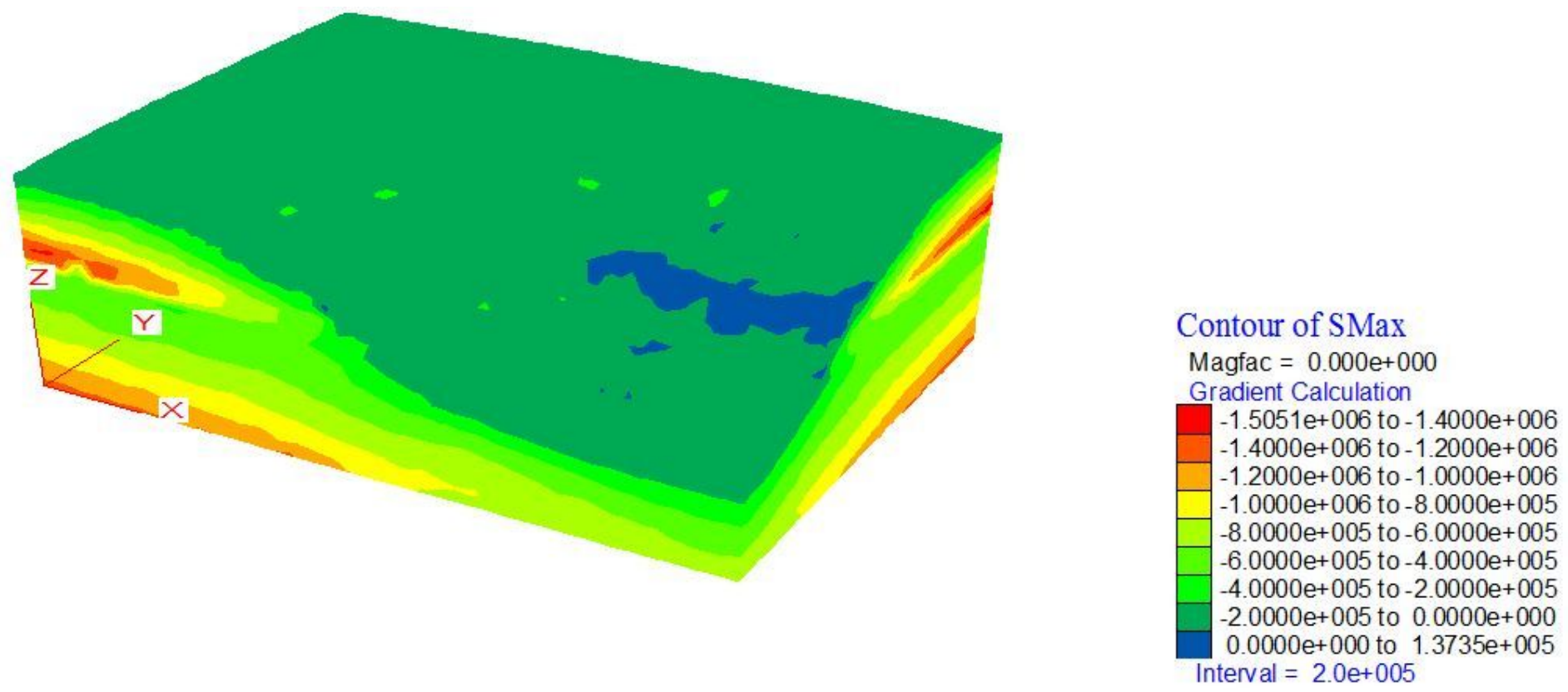

Figure 19

Contour of maximum principal stress under natural condition

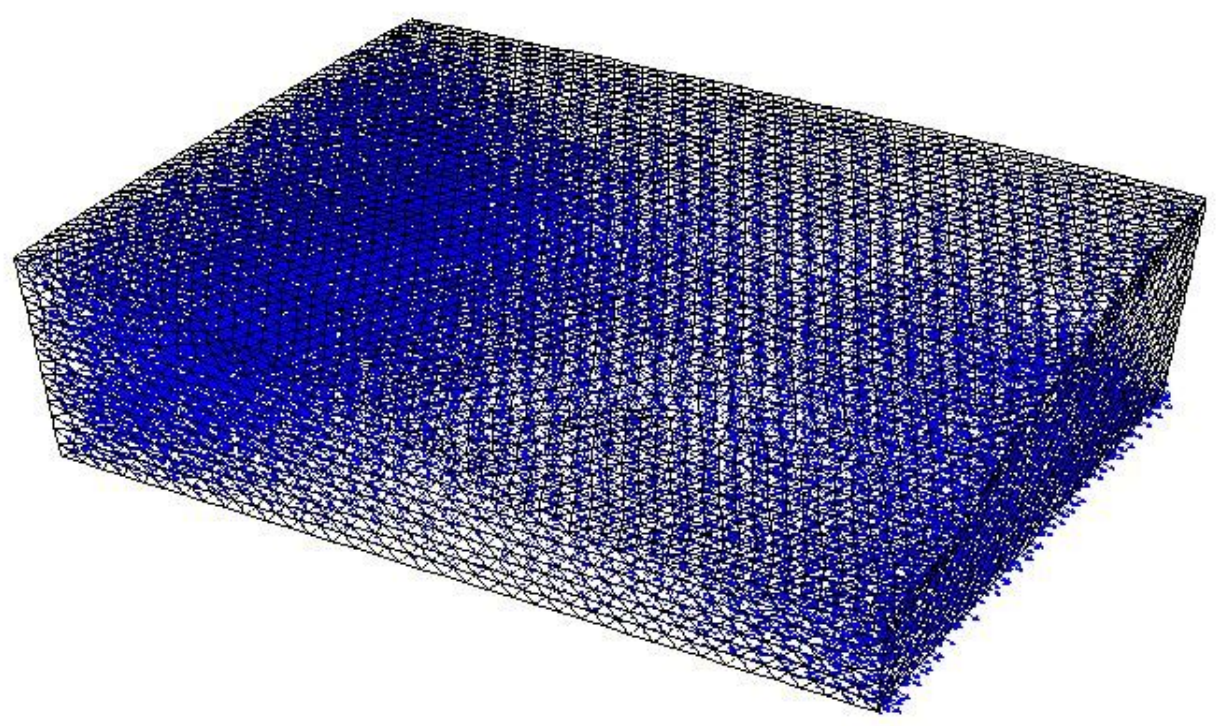

Flow Vectors

$\mathrm{M}$ aximum $=2.329 \mathrm{e}-006$ Scale to $\mathrm{M}$ ax $=7.000 \mathrm{e}-006$

Figure 20

Flow vectors of northwest slope under seepage condition 


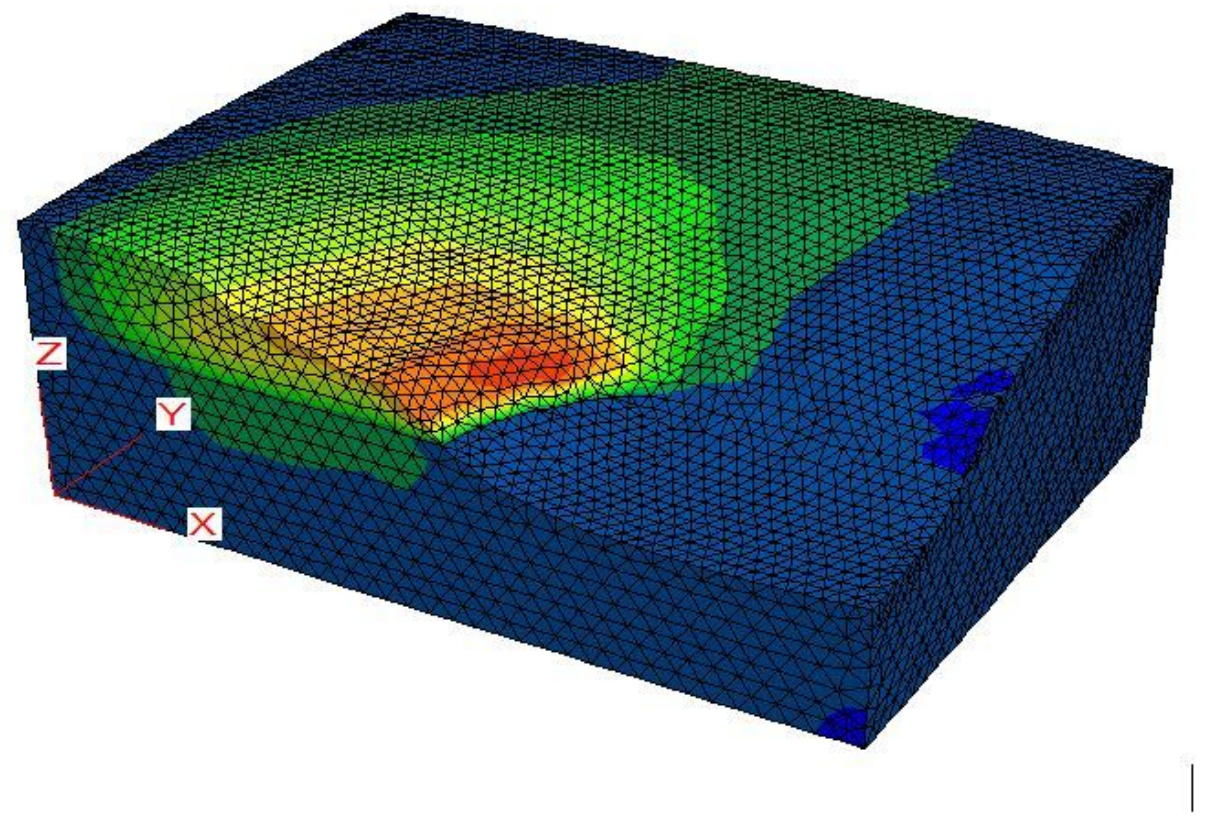

Figure 21

Contour of X-displacement of northwest slope under seepage condition

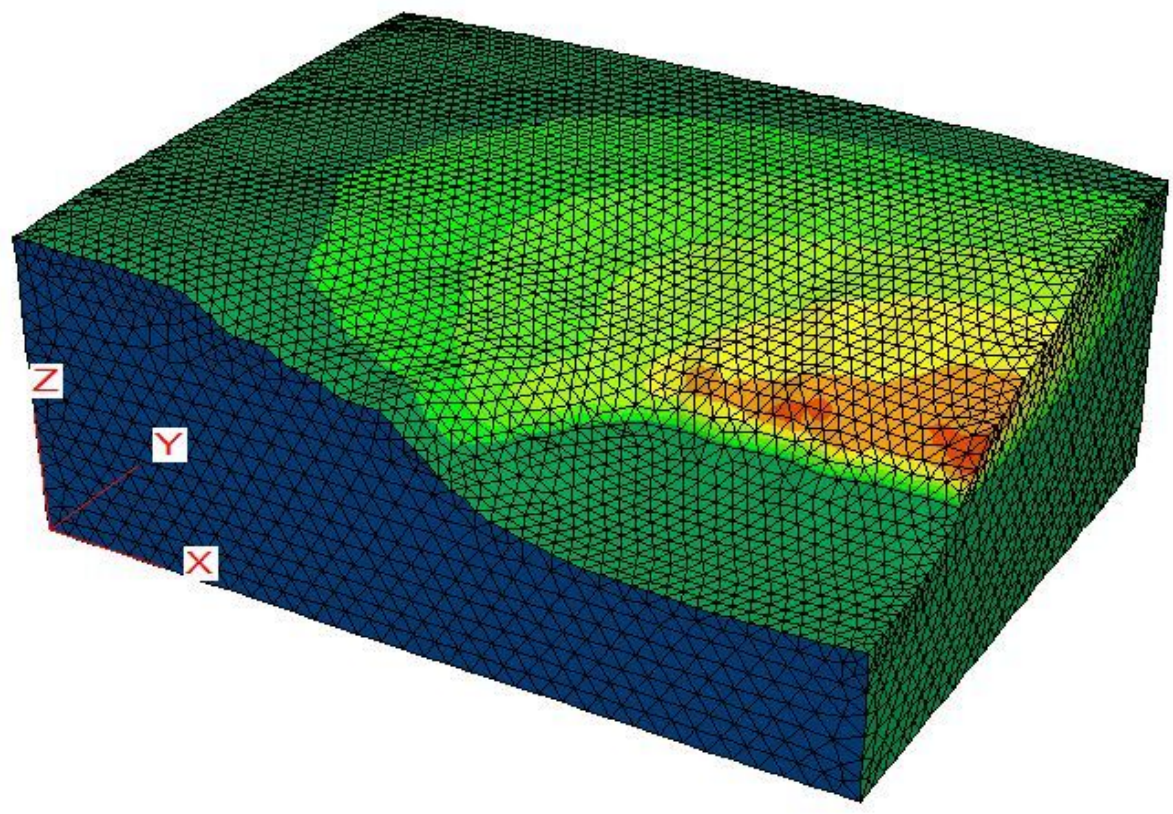

Figure 22

Contour of Y-displacement of northwest slope under seepage condition
Contour of X-Displacement Magfac $=0.000 \mathrm{e}+000$

$-1.8309 \mathrm{e}-002$ to $0.0000 \mathrm{e}+000$ $0.0000 \mathrm{e}+000$ to $5.0000 \mathrm{e}-002$ $5.0000 \mathrm{e}-002$ to $1.0000 \mathrm{e}-001$ $1.0000 \mathrm{e}-001$ to $1.5000 \mathrm{e}-001$ $1.5000 \mathrm{e}-001$ to $2.0000 \mathrm{e}-001$ $2.0000 \mathrm{e}-001$ to $2.5000 \mathrm{e}-001$ $2.5000 \mathrm{e}-001$ to $3.0000 \mathrm{e}-001$ $3.0000 \mathrm{e}-001$ to $3.5000 \mathrm{e}-001$ $3.5000 \mathrm{e}-001$ to $4.0000 \mathrm{e}-001$ $4.0000 \mathrm{e}-001$ to $4.4681 \mathrm{e}-001$ Interval $=5.0 \mathrm{e}-002$

Contour of Y-Displacement Magfac $=0.000 \mathrm{e}+000$

$-7.1589 \mathrm{e}-001$ to $-7.0000 \mathrm{e}-001$
$-7.0000 \mathrm{e}-001$ to $-6.0000 \mathrm{e}-001$
$-6.0000 \mathrm{e}-001$ to $-5.0000 \mathrm{e}-001$
$-5.0000 \mathrm{e}-001$ to $-4.0000 \mathrm{e}-001$
$-4.0000 \mathrm{e}-001$ to $-3.0000 \mathrm{e}-001$
$-3.0000 \mathrm{e}-001$ to $-2.0000 \mathrm{e}-001$
$-2.0000 \mathrm{e}-001$ to $-1.0000 \mathrm{e}-001$
$-1.0000 \mathrm{e}-001$ to $0.0000 \mathrm{e}+000$
$0.0000 \mathrm{e}+000$ to $0.0000 \mathrm{e}+\infty 00$
Interval $=1.0 \mathrm{e}-001$




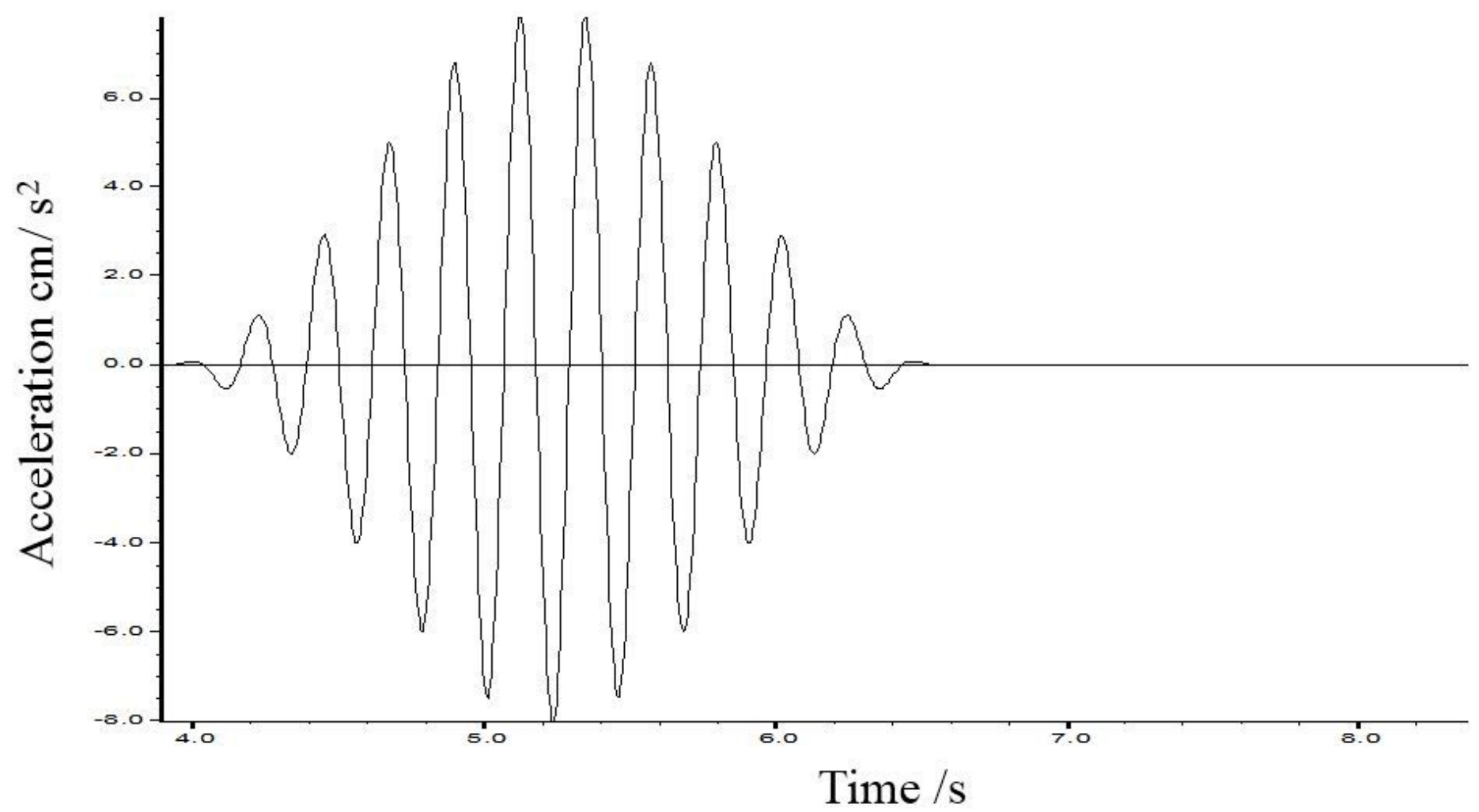

Figure 23

Horizontal earthquake acceleration curve at model bottom

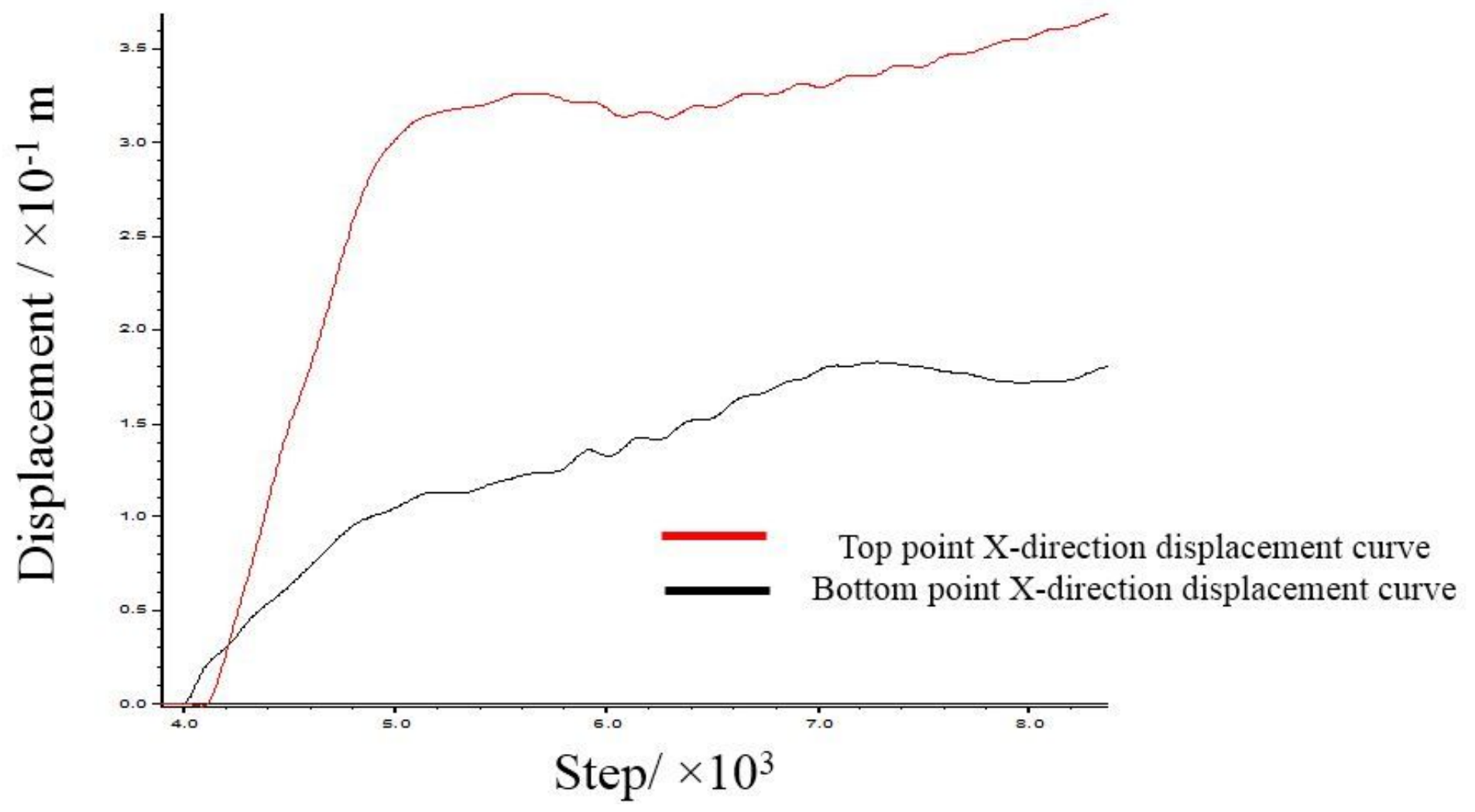

Figure 24 
X-displacement curves of bottom and top points of west slope

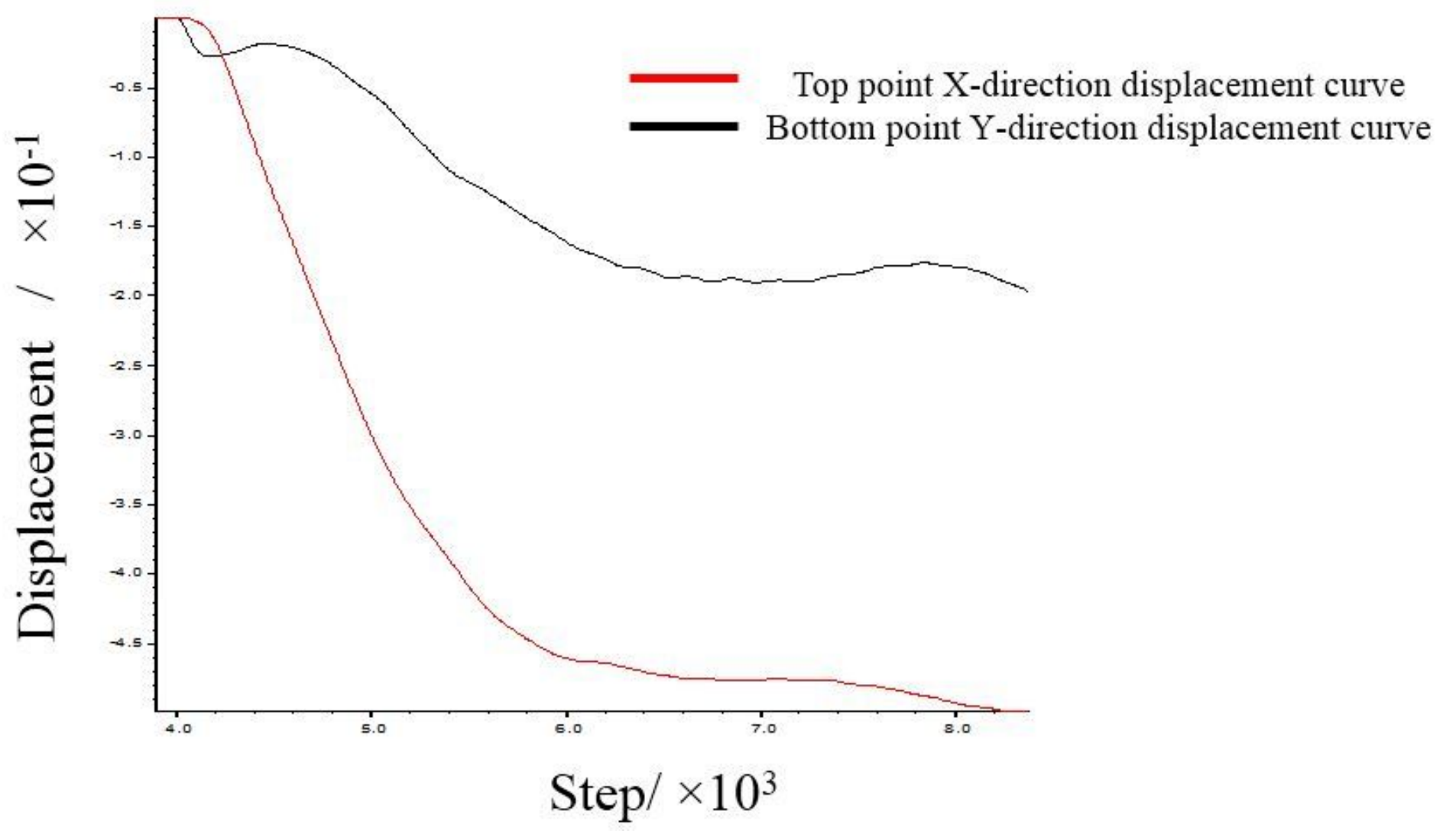

Figure 25

Y-displacement process curves of bottom point and top point in north slope Table 1 The magnitude of source area and its MPHA of Pingshuo mining 